\title{
Cleaning of toothpaste from vessel walls by impinging liquid jets and their falling
} films: Quantitative modelling of soaking effects

Yang, Jifeng; Bhagat, Rajesh K.; Fernandes, Rubens R.; Nordkvist, Mikkel; Gernaey, Krist V.; Krühne, Ulrich; Wilson, D. lan

Published in:

Chemical Engineering Science

Link to article, DOI:

10.1016/j.ces.2019.08.006

Publication date:

2019

Document Version

Peer reviewed version

Link back to DTU Orbit

Citation (APA):

Yang, J., Bhagat, R. K., Fernandes, R. R., Nordkvist, M., Gernaey, K. V., Krühne, U., \& Wilson, D. I. (2019).

Cleaning of toothpaste from vessel walls by impinging liquid jets and their falling films: Quantitative modelling of soaking effects. Chemical Engineering Science, 208, [115148]. https://doi.org/10.1016/j.ces.2019.08.006

\section{General rights}

Copyright and moral rights for the publications made accessible in the public portal are retained by the authors and/or other copyright owners and it is a condition of accessing publications that users recognise and abide by the legal requirements associated with these rights.

- Users may download and print one copy of any publication from the public portal for the purpose of private study or research.

- You may not further distribute the material or use it for any profit-making activity or commercial gain

- You may freely distribute the URL identifying the publication in the public portal 


\section{Cleaning of toothpaste from vessel walls by impinging liquid jets and their 2 falling films: quantitative modelling of soaking effects}

3 Jifeng Yang ${ }^{1}$, Rajesh K. Bhagat ${ }^{2}$, Rubens R. Fernandes ${ }^{2}$, Mikkel Nordkvist ${ }^{3}$, Krist V. Gernaey ${ }^{1}$, Ulrich

4 Krühne $^{1}$, D. Ian Wilson ${ }^{2 *}$

$5{ }^{1}$ Department of Chemical and Biochemical Engineering, Technical University of Denmark, Building 6229,2800 Kgs. Lyngby, Denmark

$7 \quad{ }^{2}$ Department of Chemical Engineering and Biotechnology, Philippa Fawcett Drive, Cambridge CB3 0AS, $8 \quad$ UK

$9 \quad{ }^{3}$ Alfa Laval Copenhagen A/S, Maskinvej 5, 2860 Søborg, Denmark

$10 *$ Corresponding author: diw11@cam.ac.uk

12 Abstract

13 The cleaning of thin toothpaste soiling layers from vertical glass surfaces by horizontal impinging water 14 jets and the falling films created by the draining liquid were studied. The effect of soaking time on the 15 rheological properties of the soil material, the force required to remove it, and the cleaning behaviour 16 were determined. The adhesive removal model reported by Wilson et al. (2014, Chem. Eng. Sci., Vol. 109, 183-195) and Bhagat et al. (2017, Food Bioprod. Proc., Vol. 102, 31-54) gave a good description 18 of the cleaning behaviour, including the shape of the cleaning front generated by jets from static and 19 moving nozzles. This model was also applied to removal by the falling liquid film: when soaking kinetics are taken into consideration, it gives a good description of this process as well. This is the first study considering the effect of soil soaking on cleaning by water jets and falling films.

22 Keywords: Cleaning; Impinging jet; Falling film; Soaking; Toothpaste 


\section{Nomenclature}

Roman

\begin{tabular}{|c|c|}
\hline$a$ & Cleaning distance, $[\mathrm{m}]$ \\
\hline$a_{X}$ & Distance to cleaning front on moving jet path, $[\mathrm{m}]$ \\
\hline$A$ & Lumped parameter, defined $A=1-10 \pi \mu r_{0} / 3 \dot{m},[-]$ \\
\hline$A_{\text {blade }}$ & Area of millimanipulation blade tip, $\left[\mathrm{m}^{2}\right]$ \\
\hline$B$ & Lumped parameter, defined $B=10 \pi \mu / 3 \dot{m} r_{0}{ }^{2},[-]$ \\
\hline$C_{1}$ & Constant, defined $C_{1}=\int_{0}^{1} f(\eta)^{2} d \eta,[-]$ \\
\hline$C_{2}$ & Constant, defined $C_{2}=\int_{0}^{1} f(\eta) d \eta,[-]$ \\
\hline$d$ & Jet diameter, $[\mathrm{m}]$ \\
\hline$f_{c}$ & Fraction of flow in core film, [-] \\
\hline$F_{W}$ & Force per unit width measured, $\left[\mathrm{N} \mathrm{m}^{-1}\right]$ \\
\hline$F_{W, \text { normal }}$ & Normal force per unit width, $\left[\mathrm{N} \mathrm{m}^{-1}\right]$ \\
\hline$F_{W, \text { shear }}$ & Shear force per unit width, $\left[\mathrm{N} \mathrm{m}^{-1}\right]$ \\
\hline$g$ & Gravitational acceleration, $\left[\mathrm{m} \mathrm{s}^{-2}\right]$ \\
\hline$G^{\prime}$ & Elastic modulus, $[\mathrm{Pa}]$ \\
\hline$G^{\prime \prime}$ & Viscous modulus, $[\mathrm{Pa}]$ \\
\hline$h$ & Film thickness, $[\mathrm{m}]$ \\
\hline$h_{\text {Kapitza }}$ & Mean film thickness, Kapitza's theory, [m] \\
\hline$h_{N u s s e l t}$ & Mean film thickness, Nusselt's theory, [m] \\
\hline$k_{0}$ & Lumped cleaning rate parameter, $\left[\mathrm{m} \mathrm{s} \mathrm{kg}^{-1}\right]$ \\
\hline$k_{1}$ & Lumped cleaning rate parameter, $\left[\mathrm{m} \mathrm{kg}^{-1}\right]$ \\
\hline$k^{\prime}$ & Lumped cleaning rate constant, $\left[\mathrm{m} \mathrm{s} \mathrm{kg}^{-1}\right]$ \\
\hline$L_{\text {blade }}$ & Length of millimanipulation blade in contact with soil, $[\mathrm{m}]$ \\
\hline$\dot{m}$ & Mass flow rate, $\left[\mathrm{kg} \mathrm{s}^{-1}\right]$ \\
\hline$M$ & Momentum flow per unit width, $\left[\mathrm{kg} \mathrm{s}^{-2}\right]$ \\
\hline$M_{y}$ & Yield momentum flow rate, $\left[\mathrm{kg} \mathrm{s}^{-2}\right]$ \\
\hline$p$ & Radial distance to cleaning front, $[\mathrm{m}]$ \\
\hline
\end{tabular}




\begin{tabular}{|c|c|}
\hline$q$ & Volumetric flow rate per unit width, $\left[\mathrm{m}^{2} \mathrm{~s}^{-1}\right]$ \\
\hline$Q$ & Volumetric flow rate, $\left[\mathrm{m}^{3} \mathrm{~s}^{-1}\right]$ \\
\hline$r$ & Radial coordinate, $[\mathrm{m}]$ \\
\hline$r_{0}$ & Nozzle radius, $[\mathrm{m}]$ \\
\hline$r_{b}$ & Radius where boundary layer reaches the free surface, $[\mathrm{m}]$ \\
\hline$r_{t}$ & Transition radius from laminar to turbulent regime, $[\mathrm{m}]$ \\
\hline$R$ & Radius of impingement region, $[\mathrm{m}]$ \\
\hline$R e_{f}$ & Film Reynolds number defined by $R e_{f}=4 \rho q / \mu,[-]$ \\
\hline$R e_{j}$ & Jet Reynolds number, [-] \\
\hline$t$ & Time, $[\mathrm{s}]$ \\
\hline alling film & Cleaning time by falling film, $[\mathrm{s}]$ \\
\hline$t_{\text {soak }}$ & Soaking time, $[\mathrm{s}]$ \\
\hline$u$ & Flow velocity, $\left[\mathrm{m} \mathrm{s}^{-1}\right]$ \\
\hline$U_{0}$ & Mean flow velocity from jet, $\left[\mathrm{m} \mathrm{s}^{-1}\right]$ \\
\hline$U_{a v}$ & Mean flow velocity, $\left[\mathrm{m} \mathrm{s}^{-1}\right]$ \\
\hline$U_{s}$ & Surface velocity, $\left[\mathrm{m} \mathrm{s}^{-1}\right]$ \\
\hline$v_{\text {blade }}$ & Millimanipulation blade velocity, $\left[\mathrm{m} \mathrm{s}^{-1}\right]$ \\
\hline$v_{\text {jet }}$ & Nozzle traverse velocity, $\left[\mathrm{m} \mathrm{s}^{-1}\right]$ \\
\hline$w_{c}$ & Width of cleaned region by moving jet, $[\mathrm{m}]$ \\
\hline$W$ & Falling film width, $[\mathrm{m}]$ \\
\hline$W_{\text {blade }}$ & Width of millimanipulation blade, $[\mathrm{m}]$ \\
\hline$W_{c}$ & Core film width, [m] \\
\hline$x, y, z$ & Cartesian co-ordinates, $[\mathrm{m}]$ \\
\hline
\end{tabular}


Greek

$\alpha \quad$ Lumped parameter, defined $\alpha=9 k^{\prime} \dot{m}^{3} / 50 \pi^{3} \rho \mu$

$\beta \quad$ Angle to direction of nozzle motion, [-]

$\gamma \quad$ Surface tension (liquid/vapour), $\left[\mathrm{N} \mathrm{m}^{-1}\right]$

$\dot{\gamma} \quad$ Apparent shear rate, $\left[\mathrm{s}^{-1}\right]$

$\delta \quad$ Boundary layer thickness, [m]

$\delta_{\text {soil }} \quad$ Soil thickness, $[\mathrm{m}]$

$\delta_{\text {gap }} \quad$ Gap between blade and substrate, [m]

$\eta \quad$ Dimensionless distance normal to the wall, defined $\eta=y / \delta,[-]$

$\eta_{\text {app }} \quad$ Apparent viscosity, [Pa s]

$\theta \quad$ Contact angle, [-]

$\mu \quad$ Dynamic viscosity, [Pa s]

$\rho \quad$ Density, $\left[\mathrm{kg} \mathrm{m}^{-3}\right]$

$\sigma \quad$ Lumped cleaning rate parameter, defined $\sigma=3 k^{\prime} \dot{m} U_{0} / 5 \pi,\left[\mathrm{m}^{2} \mathrm{~s}^{-1}\right]$

$\tau_{c} \quad$ Critical stress, $[\mathrm{Pa}]$

$\dot{\tau} \quad$ Rate of increase of shear stress, $\left[\mathrm{Pa} \mathrm{min}{ }^{-1}\right]$

$\chi \quad$ Phase angle, $\left[^{\circ}\right]$

$\Gamma \quad$ Wetting rate, $\left[\mathrm{kg} \mathrm{m}^{-1} \mathrm{~s}^{-1}\right]$

$\Gamma_{\text {core }} \quad$ Wetting rate in core film, $\left[\mathrm{kg} \mathrm{m}^{-1} \mathrm{~s}^{-1}\right]$

$\Gamma_{\text {rope }} \quad$ Wetting rate in rope, $\left[\mathrm{kg} \mathrm{m}^{-1} \mathrm{~s}^{-1}\right]$

\section{Acronyms}

BLFR Boundary layer formation region

CTS Confocal thickness sensor

RFZ Radial flow zone 
2 Liquid jets are widely used in cleaning operations to remove soil layers from the internal surfaces of 3 tanks and other vessels as well as exposed surfaces of process equipment. Devices commonly employed 4 for tank cleaning operations by liquid jets include static spray balls and rotary jet heads. The selection of 5 the device is determined by the shape and size of the unit as well as the nature of the soil on the surface 6 to be cleaned.

7 There has been a noticeable increase in research activity on flow patterns and cleaning behaviour 8 associated with a single coherent liquid jet. These studies can be categorised as either: $(i)$ cleaning in the impingement area, where the jet hits the surface and flows radially outwards (Bhagat et al., 2017; Chee et al., 2019; Feldung Damkjær et al., 2017; Gerhards et al., 2019; Köhler et al., 2016; Rodgers et al., 2018; Wang et al., 2013b); or (ii) cleaning by the falling film that exists below the impingement point, where the liquid flows down under gravity and wets a vertical or inclined wall (Morison and Thorpe, 2002; Wang et al., 2013a).

Wilson et al. (2012) presented a simple model of the radial flow region to predict the hydraulic jump radius and the minimum width of the falling film based on momentum balances. In the radial flow region the flow was treated as a laminar film with a parabolic velocity profile, which was revised by Bhagat and Wilson (2016) to include the development of a laminar boundary layer and the transition to turbulent flow in the thin film. Wilson et al. (2014) used their flow result to develop a model for adhesive removal where the driving force for detachment is the momentum force applied at the cleaning front. They applied this to data obtained with a number of soft-solid soil layers. Glover et al. (2016) extended it to the case of viscoplastic soil layers. The removal model has also been extended to include nozzle motion (Wilson et al., 2015) and the angle of inclination of the jet to the wall (Wang et al., 2015). Liquid losses due to jet breakup at longer jet lengths observed in industrial tank cleaning were included via an effective flow rate term (Feldung Damkjær et al., 2017).

The aim of this work was to develop a cleaning rate model for toothpaste, based on the adhesive removal models of Wilson et al. (2014) and Bhagat et al. (2017). Toothpaste is a dense suspension of abrasive particles (with mean size between 10-20 $\mu \mathrm{m}$ ) in a water soluble continuous phase, typically glycerine. 28 This formulation introduces dissolution and dispersion mechanisms into the removal behaviour: it 
1 represents a soil which interacts with the cleaning solution, weakening as a result of soaking time. As 2 such it represents a model material for studying the interaction of cleaning timescales with weakening 3 phenomena. This is important for industrial application as cleaning solutions often feature formulations

4 which promote weakening by adjusting $\mathrm{pH}$, solubility and wetting behaviour so there is a dynamic 5 variation in removal behaviour (Yang et al., 2019). This is particularly important for the soil layer below 6 the point of jet impingement, which is subject to soaking by the falling film. Chee et al. (2019) 7 demonstrated the importance of soaking for removal of layers of a viscoplastic soil layer (a Carbopol ${ }^{\circledR}$ 8 gel).

9 This paper presents a systematic experimental investigation of the impact of soaking on jet removal in 10 thin soil layers. The removal model is verified using cleaning tests employing static impinging jets, where 11 the soil layer has been contacted with water for different times before removal. The time dependency of 12 the model parameters is characterised. The model is then applied to cleaning by moving jets and falling 13 films, and is shown to give good agreement with the experimental data.

2. Model description

2.1. Flow patterns induced by impinging jets

17 The flow pattern generated by a horizontal jet impinging on a vertical wall is illustrated in Fig. 1. A radial flow zone (RFZ) of radius $R$ is formed around the impingement point, where the liquid moves rapidly outwards and terminates at a jump. In the RFZ, the effect of gravity is negligible, so the model also applies to a vertical jet impinging on a horizontal wall (Fig. 1(a)). Gravity determines what happens beyond the RFZ. Above the point of impingement a rope or corona with varying thickness and width forms around the RFZ, containing the liquid crossing the jump. Below the point of impingement, the jump height decreases rapidly and changes to a falling film driven by gravity. The falling film flow features two regions: ( $i$ ) the outer bounding flow, which is the extension of the rope, and (ii) the inner section, here termed the core, of width $W_{c}$ and film thickness noticeably smaller than the rope. The 26 characteristics of the falling film in systems similar to that used here have been reported by Wang et al., (2013b, 2013a) and Aouad et al. (2016). 
1 In cases where the downward flow momentum is comparable or smaller than the force due to surface 2 tension, the film width may narrow gradually to a thin tail, termed rivulet flow (Mertens et al., 2005), or 3 the film may split, creating a dry patch (Wang et al., 2013a). The formation of different falling film 4 types depends on the flow rate, losses due to jet breakup and rebound, liquid and surface characteristics.

5 This study employed flat glass substrates which gave wide films that extended downwards for long 6 distances (many $R$ ) before starting to narrow. A pseudo-stable gravity falling film of constant width $W_{c}$ 7 is formed with an assumed flow rate that is half the flow rate in the jet (the other half is in the ropes) 8 (Wang et al., 2013b).

\subsection{Adhesive removal model}

11 Glover et al. (2016) modelled removal of a viscoplastic soil layer in terms of adhesive failure, where the 12 change in the size of the cleaned region is determined by the force acting on the soil at the soil-substrate13 liquid contact line. The force is assumed to be proportional to the flow of momentum in the liquid film 14 at the cleaning front, viz:

$$
\frac{d a}{d t}=k^{\prime}\left(M-M_{\mathrm{y}}\right)
$$

Equ. 1

15 In the RFZ $a$ is the radial distance from the point of impingement to the cleaning front at time $t ; k^{\prime}$ is a 16 lumped cleaning rate constant; $M$ and $M_{\mathrm{y}}$ are the momentum flow of liquid per unit width at $a$ and the minimum momentum flow per unit width that needs to be overcome to yield the soil layer and promote cleaning, respectively. The value of $k^{\prime}$ is related to the soil layer thickness and the soil-substrate interactions. Since the same soil thickness was employed in the cleaning tests reported here, $k^{\prime}$ is expected to depend only on soaking time, $t_{\text {soak }}$. A linear dependency is assumed in the absence of supporting theory, giving

$$
k^{\prime}=k_{0}+k_{1} \cdot t_{\text {soak }}
$$

where $k_{0}$ and $k_{1}$ are positive constants, obtained by fitting experimental data. Soaking is therefore expected to increase the local rate of cleaning, reflecting a reduction in adhesive strength with time.

The flow of momentum of liquid per unit width, $M$, is calculated from: 


$$
M=\int_{0}^{h} \rho u^{2} d y
$$

1 where $h$ is the thickness of the liquid film; $\rho$ the liquid density and $u$ the velocity parallel to the wall at 2 distance $y$ from the wall. The model presented by Wilson et al. (2014) did not consider a contribution

3 from yield momentum, $M_{y}$, when cleaning polyvinyl acetate, xanthan gum and petroleum jelly layers 4 from polymethylmethacrylate (Perspex) and glass plates. Glover et al. (2016) observed asymptotic 5 cleaning behaviour in their tests on viscoplastic layers (with a different petroleum jelly) and introduced the $M_{y}$ term. Toothpastes have been reported to exhibit viscoplastic behaviour (Ahuja and Potanin, 2018; Palabiyik et al., 2014) so the $M_{y}$ term is retained. Since toothpaste contains water soluble components, $M_{y}$ is also assumed to depend on $t_{\text {soak }}$.

\subsection{Cleaning model, static nozzle}

11 Fig. 1(a) illustrates the flow pattern around the impingement point on a flat surface. The flow is divided 12 into four regions: (1) the stagnation region, (2) the boundary layer formation region (BLFR), (3) the 13 laminar region, and (4) the turbulent region. The radial flow zone terminates at a hydraulic jump due to 14 a balance between liquid momentum and surface tension (Bhagat and Wilson, 2016). Beyond the jump 15 the liquid forms a rope or continues as a falling film.

16 In the stagnation region, the flow velocity is that in the jet, $U_{0}$. In the BLFR, a boundary layer of thickness

$17 \delta$ grows, where $\delta$ increases with $r$. The radial velocity increases across the boundary layer from 0 at the wall to $U_{0}$ at $\delta$ and beyond. The BLFR ends at radius $r_{b}$ where the boundary layer reaches the film surface. Beyond $r_{b}$ the liquid flows as a fully developed laminar film, which becomes turbulent at $r_{t}$. The turbulent flow region ceases at the jump radius $R$. It should be noted that $R$ could be smaller than $r_{b}$ or $r_{t}$. Expressions for $\delta, r_{b}, r_{t}$ and $R$ are given by Equ. 4 - Equ. 7.

$$
\begin{array}{cc}
\delta=2.12 \sqrt{\mu r / \rho U_{0}} & \text { Equ. } 4 \\
r_{b} / d=0.24 R e_{j}^{1 / 3} & \text { Equ. } 5 \\
r_{t} / d=0.2964 R e_{j}^{1 / 3} & \text { Equ. } 6
\end{array}
$$




$$
R=0.276\left[\frac{\dot{m}^{3}}{\mu \rho \gamma(1-\cos \theta)}\right]^{1 / 4}
$$

1 Here $r$ is the radial coordinate, $\dot{m}$ is the mass flow rate in the jet, $\gamma$ is the surface tension between the 2 liquid and vapour, and $\theta$ is the contact angle. The jet Reynolds number is defined as $R e_{\mathrm{j}}=\rho d U_{0} / \mu$, 3 with $\mu$ being the dynamic viscosity of the liquid. It should be noted that the expression for $R$ in Equ. 7 , 4 from Wilson et al. (2012), is an approximate result: a more precise estimate requiring numerical solution 5 was presented by Bhagat and Wilson (2016) and a detailed theoretical treatment which shows that the 6 contact angle does not play a role in the formation of the jump is given by Bhagat et al. (2018). Assuming 7 a contact angle of $90^{\circ}$ produces essentially the same estimate for the films studied here.

8 For the water flow rates used in this study, the critical lengths for the different flow regions followed $9 r_{b}<r_{t}<R$. The value of $M$ at a given $r$ in each region was computed using the relationships presented 10 in Table 1 (see Bhagat and Wilson, 2016). 
1 Table 1. Summary of equations for calculating film thickness $h$, surface velocity $U_{s}$, velocity profile $u$ and momentum per unit width $M$ in the radial flow 2 zone when cleaning by static jets. The equations are reproduced from Bhagat and Wilson (2016).

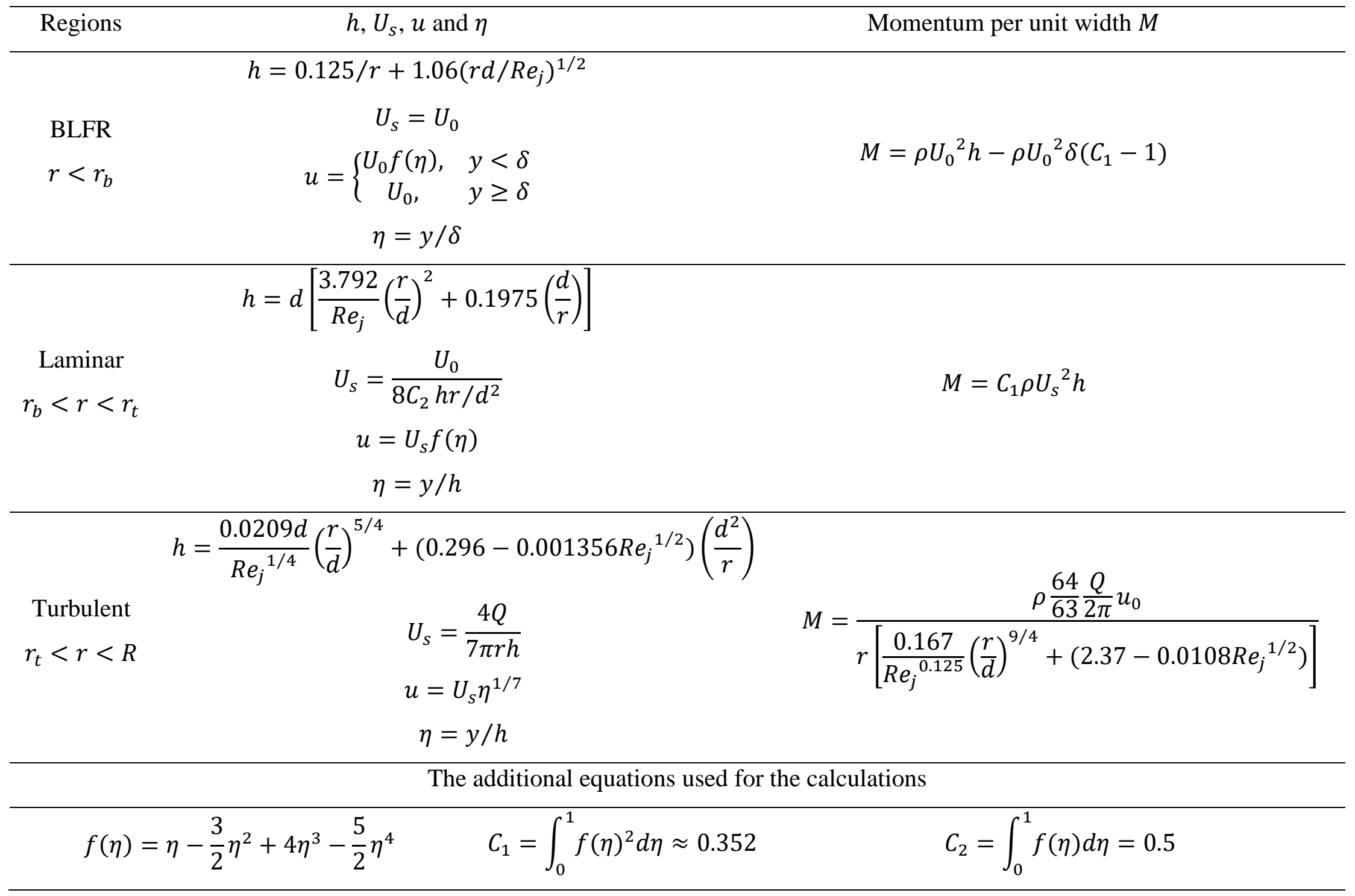




\section{$1 \quad 2.4$. Cleaning model, moving nozzle}

2 When a coherent jet impinges normally on a moving plate or the point of impingement moves across the 3 plate, a roughly elliptical cleaning front is generated ahead of the impingement point. Wilson et al. (2015) 4 modelled this scenario employing a moving frame of reference so that the point of impingement was static and the soiled surface moved toward it at relative velocity $-v_{j e t}$, as shown in Fig. 2 . Point $X$, located distance $a_{X}$ ahead of the impingement point, is a stationary point where the cleaning rate equals the nozzle velocity, i.e. $d a / d t=v_{\text {jet }}$. At point $P$, oriented at angle $\beta$ to the direction of nozzle movement and at distance $p$ from the origin, resolving the motion at steady state yields a non-linear differential equation (Bhagat et al., 2017; Wilson et al., 2015):

$$
\frac{d p}{d \beta}=\left(\frac{d a}{d t}\right)_{P} \frac{p}{v_{j e t} \sin \beta}-\frac{p}{\tan \beta}
$$

10 Computing the solution to Equ. 8 requires knowledge of the variation of $M$ with $p$. Using the expressions 11 in Table 1 to calculate $M$ requires numerical evaluation. In this work, the 'intermediate strength soil' 12 model presented by Bhagat et al. (2017) is used to estimate $\left(\frac{d a}{d t}\right)_{P}$, the local cleaning rate at the cleaning 13 front, adding a yield term $M_{y}$ to the original expression, viz.:

$$
\left(\frac{d a}{d t}\right)_{P}=\frac{\sigma}{p\left(A+B p^{3}\right)}-k^{\prime} M_{y}
$$

where $\sigma, A$ and $B$ are groups of parameters related to the cleaning rate: $\sigma=3 k^{\prime} \dot{m} U_{0} / 5 \pi, A=1-$ $10 \pi \mu r_{0} / 3 \dot{m}$, and $B=10 \pi \mu / 3 \dot{m} r_{0}{ }^{2}$. At $X$, Equ. 9 yields:

$$
\left(\frac{d a}{d t}\right)_{X}=v_{j e t}=\frac{\sigma}{a_{X}\left(A+B a_{X}^{3}\right)}-k^{\prime} M_{y}
$$

16 The distance to the cleaning front on jet path, $a_{X}$, can be solved analytically using Equ. 10. The shape of 17 the cleaning front can be calculated by substituting Equ. 9 into Equ. 8 with initial condition $p=a_{X}$ at $18 \beta=0 . A$ and $B$ can be calculated from the jet properties so the parameters required to solve are $k^{\prime}$ and $19 M_{y}$, which can be obtained either from inspection of data generated by a static nozzle or by fitting the 20 parameters to the experimental results of cleaning by moving nozzles. 
1 The solution depends on the hydrodynamic model used. The shape of the cleaning front obtained using

2 the Bhagat and Wilson (2016) model to evaluate $M$ and $\left(\frac{d a}{d t}\right)_{P}$ is compared to that obtained using Equ. 9

3 for a case representative of the experiments reported here, and the results are compared for a case in the

4 Supplementary material, Figure S.1. The agreement is very good.

5

$6 \quad$ 2.5. Cleaning model, falling film

7 Flow in the falling film is assumed to be laminar with a parabolic velocity profile:

$$
u=\frac{\rho g}{2 \mu}\left(2 h y-y^{2}\right)
$$

8 where $g$ is the gravitational acceleration and $y$ is the distance from the wall. The average velocity in the 9 film, $U_{a v}$, is:

$$
U_{a v}=\frac{1}{h} \int_{0}^{h} u d y=\frac{\rho g h^{2}}{3 \mu}
$$

10 Giving

$$
M=\frac{6}{5} \rho U_{a v}^{2} h
$$

11 The water film thickness $h$ is now evaluated. In Nusselt's theory, the film is purely viscous, and thus a 12 flat surface is assumed (Nusselt, 1916). The mean film thickness is then:

$$
h_{\text {Nusselt }}=\left(\frac{3 \mu q}{\rho g}\right)^{1 / 3}
$$

Equ. 14

13 where $q$ is the volumetric flow rate per unit width. Waves were observed in the experiments: according 14 to Kapitza's theory of wavy flow, the parabolic velocity profile also applies but the mean film thickness 15 is given by (Portalski, 1963) :

$$
h_{\text {Kapitza }}=\left(\frac{2.4 \mu q}{\rho g}\right)^{1 / 3} \approx 0.928 h_{\text {Nusselt }}
$$


1 The Nusselt film thickness is therefore ca. 7\% larger than the Kapitza value. Nusselt's and Kapitza's 2 results are valid for water when the film Reynolds number $\left(R e_{f}=4 \rho q / \mu\right)$ is less than 1160 (Portalski, 3 1963). Since ropes exist on both edges of the falling film with a thickness much larger than the core film 4 (see Fig. 1(c)), only the momentum per unit width in the core film region is calculated. $q$ is estimated 5 using $q=f_{c} \dot{m} / \rho W_{c}$, where the width of the core film, $W_{c}$, is determined experimentally. The fraction of the jet flow rate in the core film, $f_{c}$, is assumed to be $50 \%$. Any losses due to splashing are ignored (Wang et al., 2013b).

9 3. Materials and methods

\subsection{Rheology}

11 The rheology of the toothpaste (Advanced White, Colgate) was measured on a rotational rheometer 12 (Kinexus lab+, Malvern Panalytical, UK) using roughened parallel plates at $20^{\circ} \mathrm{C}$ with $1 \mathrm{~mm}$ gap. The 13 solids content of the toothpaste sample was $62.1 \pm 4.5 \mathrm{w} / \mathrm{w} \%$. The measurements included undiluted or 14 diluted (10 - 50\% extra water) samples without pre-shear, as well as undiluted toothpaste with pre-shear at $5 \mathrm{~Pa}$ for $3 \mathrm{~min}$ (see Table 3). Pre-shear at $5 \mathrm{~Pa}$ was based on the estimated wall shear stress imposed by the falling film under the jet flow rates considered (around $3 \mathrm{~Pa}$ ).

17 First, an oscillatory time sweep was applied with a stress amplitude of $0.1 \mathrm{~Pa}$ at a frequency of $1 \mathrm{~Hz}$ for 183 min to identify the viscous and elastic characteristics of the sample. A stress ramp was then applied, increasing the shear stress at a rate of $\dot{\tau}=10 \mathrm{~Pa} \cdot \mathrm{min}^{-1}$ from $0.25 \mathrm{~Pa}$ until the material yielded. Hysteresis tests were also performed, imposing an increasing and then decreasing ramp for a shear rate between 0.01 and $100 \mathrm{~s}^{-1}$, to test the macro- or micro-structural rearrangement of the material over time.

\subsection{Millimanipulation}

The millimanipulation device reported by Magens et al. (2017) offers a method for determining the forces required to remove the soiling layer. Fig. 3 is a schematic of the device operation. The sample was spread 
1 the plate at constant velocity $v_{\text {blade }}$ with a defined gap between the blade base and the substrate. The 2 millimanipulation device used here featured a static blade and the sample moved towards it. The force 3 imposed on the blade was measured by a force transducer (HBM S2M, Germany). The width of the blade 4 tip $W_{\text {blade }}$ was $0.140 \pm 0.017 \mathrm{~mm}$, determined by a confocal thickness sensor (CTS, IFS 2405-3, Micro5 Epsilon, Germany).

6 Millimanipulation was performed to investigate the effect of soil thickness, gap distance and soil type 7 (soaked or not) on the removal force. Measurements were made at blade velocities of $0.1,1,5$ and 10 $8 \mathrm{~mm} \cdot \mathrm{s}^{-1}$. To prepare the soaked samples, the plate was mounted in the millimanipulation chamber and the 9 chamber was filled with deionized water then emptied after 3 min using a syringe.

10 The soil deformed and accumulated in front of the blade, as shown in Fig. 3. The force measured by the sensor included three components: $(i)$ the force to deform material ahead of the blade, (ii) the force to 12 displace the deformed material, and (iii) the force to overcome the shear resistance under the tip of the

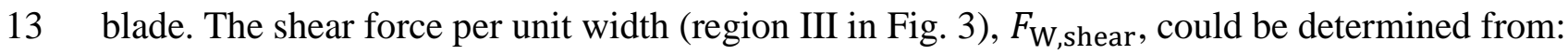

$$
F_{W, \text { shear }}=\frac{\tau A_{\text {blade }}}{L_{\text {blade }}}=\frac{\eta_{\text {app }} \dot{\gamma} L_{\text {blade }} W_{\text {blade }}}{L_{\text {blade }}}=\eta_{\text {app }} \dot{\gamma} W_{\text {blade }}
$$

14 Here, $A_{\text {blade }}$ and $L_{\text {blade }}$ are the area and length of the blade tip, respectively. $\tau$ is the shear stress under 15 the tip of the blade. The apparent viscosity, $\eta_{a p p}$, was taken from the rheological data at apparent shear rate $\dot{\gamma}=v_{\text {blade }} / \delta_{\text {gap }}$. The combined force of deforming and displacing the soil ahead of the blade (regions I and II in Fig. 3) was labelled the normal force and determined using:

$$
F_{W, \text { normal }}=F_{W}-F_{W, \text { shear }}
$$

18 The parameters studied in millimanipulation testing are summarised in Table 2. 
1 Table 2. Millimanipulation test conditions. Tests were conducted using blade velocities ranging from 0.1 2 to $10 \mathrm{~mm} \cdot \mathrm{s}^{-1}$.

\begin{tabular}{lll}
\hline Investigated parameters & Fixed parameters & Varied parameters \\
\hline Soil thickness & Soil: original toothpaste & $\delta_{\text {soil }}=200,500,700 \mu \mathrm{m}$ \\
& $\delta_{\text {gap }}=100 \mu \mathrm{m}$ & \\
\hline Gap distance & Soil: original toothpaste & $\delta_{\text {gap }}=50,100,200,400 \mu \mathrm{m}$ \\
& $\delta_{\text {soil }}=500 \mu \mathrm{m}$ & \\
\hline Soil type & $\delta_{\text {gap }}=50 \mu \mathrm{m}$ & Soil: original toothpaste and \\
& $\delta_{\text {soil }}=500 \mu \mathrm{m}$ & toothpaste soaked for 3 min \\
\hline
\end{tabular}

4 3.3. Impinging jet apparatus and experimental design

5 The pilot-scale apparatus has been described previously by Glover et al. (2016). The test plates were 6 made from transparent float glass. The dimensions of the vertical test plates were $360 \times 600 \mathrm{~mm}$, while 7 horizontal plates measured $150 \times 150 \mathrm{~mm}$. The plates were coated with toothpaste before being mounted 8 prior to cleaning. Even soil layers were prepared by dragging a blade over the plate with fixed and known 9 clearance between the blade and the plate. The resulting soil layers were approximately $500 \mu \mathrm{m}$ thick, 10 giving a mass coverage of $0.59 \pm 0.04 \mathrm{~kg} \cdot \mathrm{m}^{-2}$.

11 Cleaning experiments were performed soon after soiling (within 3 min of preparation) in order to reduce 12 drying effects. Cleaning was performed with water jets generated by a brass nozzle with diameter, $d, 2$ $13 \mathrm{~mm}$. The nozzle position could be adjusted to be horizontal or vertical. Normally impinging jets and 14 single-pass deionized water at room temperature $\left(22 \pm 2{ }^{\circ} \mathrm{C}\right)$ were used in all tests. The nozzle was located 15 approximately $10 \mathrm{~cm}$ from the test plate and generated a coherent, turbulent jet: break-up was not 16 observed. An interrupter plate was initially located between the nozzle and the soiled plate while the flow 17 was set and stabilized. The interrupter was then removed, and timing of the experiment was started 18 simultaneously.

19 Video recordings of jet impingement and cleaning were made with a digital camera (Nikon D3300 D20 SLR, Japan) located on the reverse side of the vertical plate or above the horizontal plate. Images were 21 processed using the image analysis toolbox in Matlab ${ }^{\circledR}$ (MathWorks, US). 
1 Three cleaning configurations were studied and described in sections 3.5 - 3.7: cleaning by jets from

2 static nozzles, cleaning by jets from moving nozzles, and cleaning by falling films.

$4 \quad$ 3.4. Falling film thickness measurement

5 Aouad et al. (2016) reported particle image velocimetry measurements of surface velocities in the falling 6 film region. Measuring the film thickness was complicated by the presence of gravity waves. In this 7 study, a confocal thickness sensor was used to determine the thickness of the falling film directly for 8 comparison with the Nusselt and Kapitza models. The sensor projects a polychromatic white light spot 9 on the transparent target surface, focusing each wavelength at a specific distance with controlled chromatic aberration (see Fig. 4). The sensor receives the light that is reflected from each interface and transfers this information to the controller (ConfocalDT controller 2461, Micro-Epsilon, Ortenburg, Germany). Spectral analysis is then conducted to calculate the distance between the interfaces and

13 therewith the thickness of the liquid film (Micro-Epsilon, 2016).

14 Fig. 4 shows the arrangement for measuring the thickness of the film generated on a vertical transparent 15 Perspex plate (thickness ca. $5 \mathrm{~mm}$ ) by a coherent $2 \mathrm{~L} \cdot \mathrm{min}^{-1}$ water jet generated by a $2 \mathrm{~mm}$ diameter nozzle. The sensor was located on the dry side of the plate and was traversed horizontally across the film at a distance $15 \mathrm{~cm}$ below the impingement point. Under these conditions $R$ was ca. $8 \mathrm{~cm}$ (Wang et al., 2013a), so the film was fully developed. Measurements were made at ca. $2 \mathrm{~mm}$ intervals at a sample frequency of $10 \mathrm{~Hz}$ : $h$ was determined as the average value over a $20 \mathrm{~s}$ period.

\subsection{Cleaning by jets from static nozzles}

Soiled glass plates with dimensions $150 \times 150 \mathrm{~mm}$ were used in these tests. The plate was prepared as described above and then placed flat in a basin, raised $2 \mathrm{~cm}$ from the base by aluminium blocks. Both unsoaked and soaked layers were studied. Soaking was achieved by carefully adding deionized water to the basin to submerse the soil layer, then removing the water after the required soaking time. 
1 Cleaning employed a vertical, coherent jet at a flow rate of $2 \mathrm{~L} \cdot \mathrm{min}^{-1}\left(R e_{\mathrm{j}}=21200\right)$ which impinged 2 normally at the centre of the plate. Cleaning was recorded on a digital camera located above the nozzle.

3 The cleaned region in the RFZ was found to be circular when the jet was vertical as well as horizontal.

4 The radius of the cleaned region was extracted from the video recordings.

6 3.6. Cleaning by jets from moving nozzles

7 The rectangular glass plate was soiled and mounted on an aluminium frame with its longer side vertical.

8 The nozzle was horizontal and stationary while the plate was moved vertically upwards (at $1.25 \mathrm{~cm} \cdot \mathrm{s}^{-1}$ )

9 or downwards (at $1.5 \mathrm{~cm} \cdot \mathrm{s}^{-1}$ ) by a motor.

10 The jet could impinge initially either directly on the soil layer, or above/below the soil region, as 11 illustrated in Fig. 5. When the plate moved downwards (replicating the jet moving upwards) the liquid 12 film encountered unsoaked soil. When the plate moved upwards cleaning involved both unsoaked and 13 soaked regions of soil.

14 In tests investigating the effect of pre-soaking, a falling film was generated by impinging the jet above 15 the soiled region for 1 or 2 minutes, as illustrated in Fig. 5(a). No soil was observed to be removed during 16 the pre-soaking period, and the full width of the soil layer was covered by a water film. Following soaking, 17 the upward movement of the plate was started. The width of the cleared path and the shape of the cleaning 18 front were recorded.

\subsection{Cleaning by falling films}

21 The large glass plate was mounted vertically on an aluminium frame, with a soiled region located 15 $2230 \mathrm{~cm}$ below the impingement point, as in Fig. 5(a). The flow rates investigated ranged from $0.6-2.5$ $23 \mathrm{~L} \cdot \mathrm{min}^{-1}$, corresponding to $R e_{\mathrm{j}}=6300-26500$. Only the removal of soil layers by the core falling 24 film (width $W_{\mathrm{c}}$ in Figure 1(c)) was analysed. The soiled area was divided into bands of $1 \mathrm{~cm}$ high and 25 the time taken for the whole band to be cleared (no soil visible) was denoted the cleaning time, $t_{\text {falling film }}$. 
1 The regions over which the ropes flowed were cleaned more quickly, which is consistent with the local

2 wetting rate in these areas being higher than in the core film.

3 4. Results and Discussion

4 4.1. Rheology

5 The rheological behaviour of the toothpaste and the effect of dilution are presented in Fig. 6. In the 6 oscillatory time sweep measurement, the elastic modulus $\left(G^{\prime}\right)$ and viscous modulus $\left(G^{\prime \prime}\right)$ gave steady $G^{\prime}$ 7 and $G^{\prime \prime}$ values over the test periods. The data in Fig. 6(a) show $G^{\prime}>G^{\prime \prime}$, indicating that the toothpaste can be regarded as mainly elastic at low shear stress. Both moduli decrease strongly on dilution. Pre-

9 shearing can reduce both shear moduli, but the effect is less significant than dilution.

10 The apparent viscosity data in Fig. 6(b) show shear-thinning behaviour similar to that reported by Ahuja 11 et al. (2018). The dependency of apparent viscosity on shear rate could be fitted by a Cross or Carreau 12 model. Pre-shearing of the undiluted toothpaste at $5 \mathrm{~Pa}$ for $3 \mathrm{~min}$ did not affect the trend noticeably, 13 whereas shearing at $100 \mathrm{~Pa}$ (the limit of the ramp) did: the hysteresis on the return sweep indicates a time 14 dependent behaviour of the material. Dilution also significantly decreases the apparent viscosity.

15 The shear stress at which the apparent viscosity starts to decline sharply was labelled the critical stress. 16 These values and the phase angle, $\chi=\tan ^{-1}\left(G^{\prime \prime} / G^{\prime}\right)$, at small stresses are presented in Table 3. Diluting 17 the toothpaste reduced the critical stress noticeably and increased the phase angle. These results indicated 18 that the deposit is easier to remove after soaking.

19 Table 3. Rheological characteristics of toothpaste materials. The presented data are averages and standard 20 deviations of at least two experiment repetitions.

\begin{tabular}{lll}
\hline Samples & Phase angle $\chi,\left[^{\circ}\right]$ & Critical stress $\tau_{c},[\mathrm{~Pa}]$ \\
\hline Without pre-shear, undiluted & $13.7 \pm 0.8$ & $179 \pm 1$ \\
With pre-shear, undiluted & $15.2 \pm 1.6$ & $160 \pm 6$ \\
Without pre-shear, 10\% dilution & $19.4 \pm 0.2$ & $66.5 \pm 7.5$ \\
Without pre-shear, 30\% dilution & $24.9 \pm 0.3$ & $15.3 \pm 0.7$ \\
Without pre-shear, 50\% dilution & $32.8 \pm 0.2$ & $1.65 \pm 0.05$ \\
\hline
\end{tabular}




\subsection{Millimanipulation testing}

2 The millimanipulation results in Fig. 7(a) show that the shear force under the blade is a minor 3 contribution to the force required to move the blade through the toothpaste layer. Deformation and 4 displacement of the soil dominate. Fig. 7(b) shows that the measured removal force is proportional to the

volumetric removal rate of soil displaced by the blade, calculated from $\left(\delta_{\text {soil }}-\delta_{g a p}\right) v_{\text {blade }} L_{\text {blade }}$. This force is expected to be dominated by the cohesive interactions in the toothpaste layer, which have to be overcome in order to deform the material as the blade passes through the layer and moves the deformed material up the blade.

Fig. 8 shows that the force required to remove an unsoaked layer and a layer pre-soaked for 3 min increases linearly with $v_{\text {blade }}$ in both cases, indicating that the cohesive forces in the toothpaste decrease significantly on soaking (as observed in the $G^{\prime}$ values in Fig. 6). This will be shown to be reflected in the effect of soaking on the $M_{\mathrm{y}}$ term in the adhesive cleaning model (Equ. 1).

There were noticeable amounts of residual material on the test plates after the blade had passed (see insets in Fig. 8), indicating that the adhesive interactions between the soil and substrate were weaker than the cohesion within the soil matrix. If they were comparable or stronger, a uniform film of toothpaste would be left by the blade. The amount of toothpaste remaining on the substrate decreased after soaking, indicating that both the adhesive and cohesive interactions had decreased. The results are consistent with the findings of Cuckston et al. (2019), who reported reduced removal forces after immersing a carbohydrate-fat food soil in a detergent solution for some time. These residues are not observed in the impinging jet experiments as the soil layer (and any residue) is subjected to continual hydraulic force by the liquid film: the toothpaste contained a water soluble mobile phase (glycerine) so any residue was readily dispersed by the flow of water. It is acknowledged that visual cleanliness does not equate to complete removal of all residues, as material may be present in the form of very thin layers or patches. The absence of visual residue was used here as a measure of cleaning, reflecting what is often used in industrial practice.

\subsection{Cleaning behaviour - static jet}


1 Fig. 9(a) summarises the cleaning behaviour for toothpaste layers ( $\left.\delta_{\text {soil }}=500 \mu \mathrm{m}\right)$ on a horizontal plate 2 contacted by a vertical coherent water jet at a flow rate of $2 \mathrm{~L} \cdot \mathrm{min}^{-1}\left(R e_{j}=21200\right)$. The momentum 3 per unit width $(M)$ on the abscissa was calculated using the equations in Table 1 . The results obtained 4 for layers subject to different soaking times all exhibit the linear dependency of Equ. 1, confirming that 5 the adhesive removal model gives a satisfactory description of this system.

6 The gradient and intercept of the fitted linear trend lines in Fig. 9(a) yield the cleaning rate constant, $k^{\prime}$, 7 and the product $k^{\prime} M_{y}$, respectively, which allows $M_{y}$ to be calculated. These calculation results are 8 presented in Fig. 9

9 Fig. $9(b)$ and $(c) . k^{\prime}$ increases initially linearly on soaking, and fitting Equ. 2 to the data yielded parameters $k_{0}=0.0051 \mathrm{~m} \cdot \mathrm{s} \cdot \mathrm{kg}^{-1}$ and $k_{1}=0.000094 \mathrm{~m} \cdot \mathrm{kg}^{-1}$. The product $k^{\prime} M_{y}$ passes through a minimum as $t_{\text {soak }}$ increases: the estimated value of $M_{y}$ decreases steadily with $t_{\text {soak }}$ and this was modelled as an exponential decay:

$$
M_{y}=1.03 \cdot \exp \left(-\frac{t_{\text {soak }}}{40.6}\right)+0.0291
$$

13 The uncertainties in $k^{\prime}$ and $k^{\prime} M_{y}$ combine to give large uncertainties in $M_{y}$, as displayed in Fig. $9(c)$.

14 Separate tests employing vertical walls yielded similar $k^{\prime}$ values (data not reported) so the above soaking dynamics are employed for vertical walls in subsequent sections.

It is interesting to compare the liquid film momentum $(M)$ with the force measured by millimanipulation $17\left(F_{W}\right)$, as both terms have the same unit $\mathrm{kg} \cdot \mathrm{s}^{-2}\left(=\mathrm{N} \cdot \mathrm{m}^{-1}\right)$. The comparison is shown in Fig. 8, taking $d a / d t=v_{\text {blade }}$, for cleaning by an impinging jet of an unsoaked and a soaked toothpaste layer of similar thickness to those in the millimanipulation tests. Both groups of data exhibit the linear dependency of Equ. (1) and show order of magnitude agreement. At a given blade velocity or cleaning rate, the force measured by millimanipulation is larger than the liquid film momentum calculated via Equ. 3. This is because the measured $F_{W}$ mainly quantifies the cohesive bonds within the soil matrix and the work required to move the dislodged soil over the face of the blade. The proposed adhesive removal model describing the cleaning tests assumes adhesive failure between the soil layer and the substrate. When the soil layer is dislodged as shown in Fig. 1(a), the force to be overcome by the liquid film includes the adhesive interaction and a contribution arising from cohesive failure at the cleaning front. Despite the 
1 difference in forces between millimanipulation and cleaning tests, the former technique is still a useful

2 tool to investigate the removal force and soaking effect. It also provides a lower bound on $k^{\prime}$.

4 In some tests, after some time, cleaning was observed to involve fingering. Fig. 10(a) shows an example.

5 For most cases documented in Fig. 9 (with the exception of $t_{\text {soak }}=10 \mathrm{~min}$ ), the cleaned region grew as 6 a circle, then formed unstable fingers before a maximum cleaning radius was reached. The radius where 7 fingers started to appear and the associated value of $M$ are plotted in Fig. 10(b). When a finger formed, 8 the water film was seen to penetrate beneath the soil layer and peel the soil off.

9 The radius at which fingering appeared was always smaller than $R$ and increased linearly with $t_{\text {soak }}$. The 10 appearance of fingers is related to the stability of the liquid-liquid interface (Hsu et al., 2012) and the 11 yield momentum of the soil material. This represents an area for further investigation. Fingering is undesirable in the context of cleaning as it leads to non-uniformity of removal as a result of liquid being channelled into the finger regions.

\subsection{Cleaning behaviour - moving nozzle}

The cleaning of unsoaked toothpaste by a water jet generated by a moving nozzle was observed to occur by means of two mechanisms:

\section{Pure adhesive failure (Peeling)} When the water jet initially impinged outside the soiled region and moved towards unsoaked soil so that the film jump contacted the contact line between the soil and the substrate (Fig. 5(a) and (b)), the thin film of water in the RFZ was observed to flow along the interface between the soil and substrate, detaching the soil layer via peeling, as shown in Fig. 11(a). Peeling was also observed in some cases after fingering was observed.

II Contact line erosion 
When the water jet initially impinged on the soil layer (Fig. 5(c)), the thin liquid film did not penetrate along the soil-substrate interface. Cleaning involved the continuous removal of the soil at the contact line (Fig. 11(b)). The rate of removal was smaller than by peeling. This mechanism is similar to that reported in other studies (Glover et al., 2016; Wilson et al., 2015; Wilson et al., 2014).

The difference in behaviour is related to the cohesive strength of the soil. In tests where a jet from a static nozzle impinged above the soiled region for 1 to 2 minutes so that the soil layer was soaked by the falling film before the nozzle started to move (Fig. 5(a)), no soil was removed during the initial wetting phase. When the nozzle subsequently moved over the soil, only removal by contact line erosion (Mechanism II) was observed. This change was attributed to a decrease of the cohesive strength of the soil layer as a result of soaking to the point where the layer could not be stripped off as a coherent film. This is discussed further in section 4.5 .

Fig. 12 compares the experimental results for the shape of the region cleaned by a moving nozzle with the model prediction, where the model parameters were obtained from tests conducted with a static nozzle. Peeling (Mechanism I) gives a noticeably larger cleared area. Fig. 12(a) shows results for the case where the soil being cleaned was not contacted by liquid in the falling film. The ratio of the cleared width, $w_{C}$ as indicated in Fig. 2, to $a_{X}$ in Fig. 12(a) differs between the two cases: for case I, $w_{c} / a_{X}=76 \mathrm{~mm} / 31$ $\mathrm{mm}=2.45$ while for case II, $w_{c} / a_{X}=38 \mathrm{~mm} / 12 \mathrm{~mm}=3.17$. The latter is close to the value of 3.04 reported by Bhagat et al. (2017), where the adhesive removal model was applied for cleaning 'weak' soils with $M_{y}=0$.

21 For the case II, experimental data and the profile predicted by the model (Equ. 8, with parameters from Fig. 9) show good agreement. The model results were generated by integrating Equ. 8 using Matlab ${ }^{\circledR}$

When the jet moves downwards (Fig. 12(b)), the falling film wets the soil in advance of the RFZ and this soaking is expected to increase the rate of removal. This is very evident in the data for tests showing case II behaviour, where the width of the cleared region did not reach a steady value. The profile for the case 26 I test with no soaking period is similar in shape to that in Fig. 12(a), but with $w_{c} / a_{X}=104 \mathrm{~mm} / 34 \mathrm{~mm}$ $27=3.06$. The prediction fits the case II experimental data reasonably well. 
1 These results indicate that the case II cleaning performance of a jet moving across an unsoaked or soaked 2 soil layer can be estimated with some confidence, using parameters obtained from static nozzle tests. The next stage of development would be to incorporate this prediction with a simulation that traces the path

4 of the jet and also records the region of the wall that receives the falling film.

$6 \quad 4.5$. Falling film behaviour and cleaning

$7 \quad$ Falling film thickness

8 Fig. 13 shows the film thickness measured using the CTS for a falling film generated by a $2 \mathrm{~L} \cdot \mathrm{min}^{-1}$ jet 9 on a Perspex plate. The presence of the ropes is evident on both sides of the film. The mean thickness of 10 the core film is nearly constant and agrees well with the values predicted by the Kapitza model (Equ. 15). 11 The Nusselt model (Equ. 14) over-predicts the film thickness by ca. 17\%, confirming that the surface 12 waves need to be considered when computing the film thickness. Regular wavy flow was observed during 13 all the cleaning experiments. This is represented by the percentiles of film thickness in Fig. 13. In the 14 core film, most thickness measurements $\left(75^{\text {th }} / 25^{\text {th }}\right.$ percentiles) lay within $8 \%$ of the average thickness measured by the CTS. The intensity of the waves is expressed as the difference between the $99^{\text {th }}$ and $1^{\text {st }}$ 16 percentiles, and is about $160 \%$ of the average film thickness.

17 Only two data points are reported for the rope on the left side compared to five for the right side. This is 18 because the CTS measurement sensor has a limited range, of ca $3 \mathrm{~mm}$, and the distance from the sensor to the plate, the depth of the plate, and the rope thickness exceeded this value.

20 The good agreement between the measured and predicted film thicknesses indicates that the $f_{c}$ value of 210.5 used to calculate the volumetric flow rate in the core film gives reliable estimates of the flow and 22 hence the value of $M$ to use in the cleaning model. 
1 The evolution of the cleaning of a band of soil below the point of impingement by the falling film (see 2 Fig. 5(a)) is reported in Fig. 14. Cleaning starts at $t=0$. The soil beneath the ropes is cleared more 3 quickly than that in the core region, which is consistent with the local flow rate being higher in the ropes.

4 A vertical finger is evident after $t=60 \mathrm{~s}$, which was caused by flow channelling. These channels were 5 observed in all cleaning tests, resulting in faster cleaning in the channel areas. The location and width of 6 the channels were found to be random when experiments were repeated. By $t=180 \mathrm{~s}$, more channels 7 had appeared and a cleaning front can be seen to have started to move downwards from the top of the soiled band. Over time further channels appear, existing channels widen, and the cleaning front descends more quickly as the soil weakens as a result of soaking. The regions beyond the ropes are not cleaned.

The progress of the cleaning front was quantified by sectioning the core region into $1 \mathrm{~cm}$ high horizontal

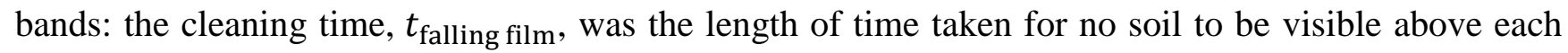
band boundary.

13 Fig. 15 shows a typical example of the observed cleaning profiles. There is an initial delay of nearly 3 min before the cleaning front starts to move. This is attributed to time taken for soaking to reduce the yield momentum, $M_{\mathrm{y}}$, to a value comparable with $M$ imposed by the film. The rheology measurements have confirmed that pre-shearing the soil material at the shear stress imposed by the falling film for 3 min did not reduce the critical stress of the toothpaste significantly (Table 3), so pre-shearing effects can be neglected.

The cleaning model, Equ. 1, with $t_{\text {soak }}$ dependent parameters given by Equ. 2 and Equ. 18, was applied to cleaning by the falling film where $M$ is calculated using Equ. 13, at approximately $0.02-0.05 \mathrm{~kg} \cdot \mathrm{s}^{-2}$ for the range of flow rates investigated. The observation of channelling suggests that the flow rate across the core film may not be uniform. Two flow rate scenarios were considered:

\section{(i) Continuous soaking (see Fig. 16(a))}

This is associated with a high flow rate in the falling film. Channelling is assumed not to affect the flow rate distribution significantly. The values of $k^{\prime}$ and $M_{y}$ are given by Equ. 2 and Equ. 18, respectively, with the former increasing and the latter decreasing with extended soaking.

(ii) Discontinuous soaking (see Fig 16(b) 
In this scenario, the soil layer is assumed to be covered by the falling film until some channels appear. Liquid is assumed to flow preferentially along the channels so that there is no further effect of soaking: $k^{\prime}$ and $M_{y}$ do not change after a certain period. The value of $M$ should also change to reflect the change in local flow rate. Detailed knowledge of the flow pattern would be needed to implement this scenario, and it would require a reliable model for channel formation. In the absence of such information, the calculations use $M$ for the uniform film.

The time when the yield momentum $M_{y}$ becomes lower than the film momentum, $M$, is labelled $t_{\mathrm{i}}$, after which the cleaning front moves down. $t_{i}$ and $M_{y}$ can be calculated via Equ. 18 by either $(i)$ setting $M_{y}=$ $M$ to solve for $t_{i}$ or, (ii) using the observed value of $t_{i}$ to calculate $M_{y}$. The challenge in applying Equ. 18 is the significant uncertainty in $M_{y}$ evident in Fig. 9(c), originating from the combined uncertainties in $k^{\prime}$ and $k^{\prime} M_{y}$. The lowest value of $M_{y}$ estimated by this method for low flow rates was higher than the film momentum calculated using Equ. 13, indicating that $t_{i}$ was infinite. This was not observed in practice, so $t_{i}$ was based on observations, and $M_{y}$ is determined by fitting experimental results. This represents an area for further work, where the influence of surface waves should be considered.

Fig. 15 shows the fits for the two scenarios alongside the experimental data for a jet flow rate of $2 \mathrm{~L} \cdot \mathrm{min}^{-}$ ${ }^{1}$. The cleaning times based on the Nusselt film thickness result are longer than the Kapitza film because the former predicts a thicker film, smaller mean flow velocity and lower $M$. The continuous soaking scenario gives rise to an increase in cleaning rate with time, whereas the discontinuous case gives a linear trend. The behaviour evidently lies somewhere between the two scenarios, and at higher flow rates (up to $2.5 \mathrm{~L} \cdot \mathrm{min}^{-1}$, Fig. 17) the continuous soaking scenario gives better agreement.

The mechanism of cleaning the toothpaste soil from vertical surfaces by the falling film can be described as involving the following steps:

1) The initial yield momentum of the soil is larger than $M$ for the falling film, so the soil is soaked but is not removed. The liquid flows over the soil layer and soaks the soil layer.

2) At $t_{i}, M_{y}$ for the soaked soil is smaller than $M$ for the film and soil starts to be removed by adhesive failure. Channelled flow appears at this time or earlier: its occurrence is determined by the heterogeneity of the soil layer and the flow pattern. 
1 3) At low flow rates, liquid tends to flow along channels, so only the cleaning front and channel boundaries are in contact with liquid. The rest of the soil layer is not soaked further and the cleaning front moves downwards at a constant rate. The channels widen progressively with time.

4) At high flow rates, a fraction of the liquid flows through the channels and the remainder flows over the soil layer. The liquid continues to soak the soil and the cleaning rate increases with time.

Fig. 17 suggests that the transition between continuous soaking and discontinuous soaking occurs at a flow rate of $2-2.5 \mathrm{~L} \cdot \mathrm{min}^{-1}$. This value can be compared with guidelines for wetting rates (i.e. mass flow rate per unit width of film) for cleaning process equipment. In these experiments, the wetting rate for the core film is $0.097-0.112 \mathrm{~kg} \cdot \mathrm{m}^{-1} \cdot \mathrm{s}^{-1}$. This is lower than the ASME BPE standard of $0.517-0.617 \mathrm{~kg} \cdot \mathrm{m}^{-}$ ${ }^{1} \cdot \mathrm{s}^{-1}$ for cleaning vertical cylindrical vessels using static spray devices (American Society of Mechanical Engineers, 2016), indicating that a device sized to the industrial standard would not encounter problems associated with channelling when cleaning a soil with properties similar to the toothpaste. Indeed, the rate of cleaning would accelerate with soaking time.

\section{Critique - cleaning by falling film}

The momentum flow rate in the water film differs significantly between the impingement area $(M>0.1$ $\left.\mathrm{kg} \cdot \mathrm{s}^{-2}\right)$ and the falling film $\left(M<0.05 \mathrm{~kg} \cdot \mathrm{s}^{-2}\right)$. It has been shown above that the adhesive removal model developed by Wilson et al. (2014) and Bhagat et al. (2017) for cleaning near the point of jet impingement also applies to the cleaning by the falling film. However, there are two challenges in using the model to describe the cleaning of toothpaste by falling films, both related to soaking. Firstly, soaking determines the initial delay before the cleaning front starts to move downwards. The duration of this soaking step is related to the flow conditions, and the mechanism behind this is not yet completely understood. Secondly, the value of the yield momentum of toothpaste after soaking, $M_{\mathrm{y}}\left(t_{\text {soak }}\right)$ is subject to large uncertainty, and a more accurate method for determining this quantity is required. The millimanipulation method gives an indication of the trends involved but does not allow the cleaning rate to be estimated reliably. 
2 The cleaning of toothpaste soils from glass surfaces by impinging water jets and falling films was studied 3 experimentally. The adhesive removal model presented by Wilson et al. (2014) and Bhagat et al. (2017) 4 gave a good description of the cleaning behaviour in the RFZ and was extended to incorporate the effect 5 of soaking and applied to removal in the falling film region below the RFZ.

6 Rheological studies confirmed that the toothpaste exhibited viscoplastic behaviour. The critical yield 7 stress decreases sharply when the sample is diluted with water, reflecting the effect of soaking on removal. 8 The effect of soaking was also evident in millimanipulation testing: this technique gave a measure of the 9 cohesive forces within the soil matrix, and confirmed that these were stronger than the adhesive 10 interaction between the soil and the plate surface.

11 Soaking was found to affect the cleaning rate constant and the yield momentum parameters in the 12 cleaning model. The values of these parameters, and their dependency on soaking time, were identified 13 with tests using jets generated by stationary nozzles. Employing these results in existing models for 14 predicting the shape of the region cleaned by a moving nozzle gave good agreement with the 15 experimental data for cases where peeling did not occur. Peeling and fingering were both observed under certain conditions with the toothpaste used, indicating that cleaning of these complex fluids is subject to 17 a range of phenomena.

The model was then extended to cleaning by the falling film, where the occurrence of channelling was 19 found to affect the results. Two scenarios were presented to represent the influence of channelling 20 effectively no effect (soaking continues unabated) and no further soaking. The former gave a more reliable description at the higher flow rates tested, which did not reach the wetting rates recommended for industrial practice: this indicates that a continual weakening scenario is expected to apply for such cases.

\section{Acknowledgements}

25 A PhD studentship and project support for JY from DRIP (Danish partnership for Resource and water efficient Industrial food Production), partly funded by the Innovation Fund Denmark (IFD) under contract No. 5107-00003B, and by the Technical University of Denmark (DTU), is gratefully 
1 acknowledged, as are $\mathrm{PhD}$ scholarships for $\mathrm{RKB}$ and $\mathrm{RRF}$ from the Commonwealth Scholarship 2 Commission and Coordenação de Aperfeiçoamento de Pessoal de Nível Superior - Brasil (CAPES) -

3 Finance Code 001, respectively. Financial support for JY's research at Cambridge was provided by the

4 Otto Mønsteds Fond (award No. 18-70-0448). Melissa Chee helped with the measurement of falling film 5 thickness.

Open Data

A statement providing a link to the data reported in this paper on the University of Cambridge Apollo data repository will be included here if the manuscript is accepted for publication.

References

Ahuja, A., Luisi, G., Potanin, A., 2018. Rheological measurements for prediction of pumping and squeezing pressures of toothpaste. J. Nonnewton. Fluid Mech. 258, 1-9. doi:10.1016/j.jnnfm.2018.04.003

Ahuja, A., Potanin, A., 2018. Rheological and sensory properties of toothpastes. Rheol. Acta 57, 1-13. doi:10.1007/s00397-018-1090-z

American Society of Mechanical Engineers, 2016. ASME BPE: Bioprocessing Equipment.

Aouad, W., Landel, J.R., Dalziel, S.B., Davidson, J.F., Wilson, D.I., 2016. Particle image velocimetry and modelling of horizontal coherent liquid jets impinging on and draining down a vertical wall. Exp. Therm. Fluid Sci. 74, 429-443. doi:10.1016/j.expthermflusci.2015.12.010

Bhagat, R.K., Perera, A.M., Wilson, D.I., 2017. Cleaning vessel walls by moving water jets: Simple models and supporting experiments. Food Bioprod. Process. 102, 31-54. doi:10.1016/j.fbp.2016.11.011

Bhagat, R.K., Wilson, D.I., 2016. Flow in the thin film created by a coherent turbulent water jet impinging on a vertical wall. Chem. Eng. Sci. 152, 606-623. doi:10.1016/j.ces.2016.06.011

Bhagat, R.K., Jha, N.K., Linden, P.F., Wilson, D.I. 2018. On the origin of the hydraulic jump in a thin liquid film, J. Fluid Mech. 851, R5. doi:10.1017/jfm.2018.558

Chee, M.W.L., Ahuja, T.V., Bhagat, R.K., Taesopapong, N., Wan, S.A., Wigmore, R.L., Wilson, D.I., 2019. Impinging jet cleaning of tank walls: effect of jet length, wall curvature and related phenomena. Food Bioprod. Process. 113, 142-153. doi:10.1016/j.fbp.2018.10.005

Cuckston, G.L., Alam, Z., Goodwin, J., Ward, G., Wilson, D.I., 2019. Quantifying the effect of solution 
formulation on the removal of soft solid food deposits from stainless steel substrates. J. Food Eng. 243, 22-32. doi:10.1016/j.jfoodeng.2018.08.018

Feldung Damkjær, N., Adler-Nissen, J., Jensen, B.B.B., Wilson, D.I., 2017. Flow pattern and cleaning performance of a stationary liquid jet operating at conditions relevant for industrial tank cleaning. Food Bioprod. Process. 101, 145-156. doi:10.1016/j.fbp.2016.11.001

Gerhards, C., Schramm, M., Schmid, A., 2019. Use of the Weibull distribution function for describing cleaning kinetics of high pressure water jets in food industry. J. Food Eng. 253, 21-26. doi:10.1016/j.jfoodeng.2019.02.011

Glover, H.W., Brass, T., Bhagat, R.K., Davidson, J.F., Pratt, L., Wilson, D.I., 2016. Cleaning of complex soil layers on vertical walls by fixed and moving impinging liquid jets. J. Food Eng. 178, 95-109. doi:10.1016/j.jfoodeng.2015.12.021

Hsu, T.T., Walker, T.W., Frank, C.W., Fuller, G.G., 2012. Role of fluid elasticity on the dynamics of rinsing flow by an impinging jet. Phys. Fluids 23, 1-10. doi:10.1063/1.3567215

Köhler, H., Stoye, H., Weyrauch, T., Boye, A., Mauermann, M., Majschak, J.P., 2016. Study on the application of cleaning models with high speed water jets to CIP-processes. Teh. Vjesn. - Tech. Gaz. 23, 349-355. doi:10.17559/TV-20140213152946

Magens, O.M., Liu, Y., Hofmans, J.F.A., Nelissen, J.A., Wilson, D.I., 2017. Adhesion and cleaning of foods with complex structure: Effect of oil content and fluoropolymer coating characteristics on the detachment of cake from baking surfaces. J. Food Eng. 197, 48-59. doi:10.1016/J.JFOODENG.2016.11.004

Mertens, K., Putkaradze, V., Vorobieff, P., 2005. Morphology of a stream flowing down an inclinded plane. Part 1. Braiding. J. Fluid Mech. 531, 49. doi:10.1017/S0022112005003873

Micro-Epsilon, 2016. Instruction Manual: confocalDT 2451/2461/2471. Ortenburg, Germany.

Morison, K.R., Thorpe, R.J., 2002. Liquid Distribution from Cleaning-in-Place Sprayballs. Food Bioprod. Process. 80, 270-275. doi:10.1205/096030802321154763

Nusselt, W., 1916. Die Oberflachenkondesation des Wasserdamffes. Zeitschrift des Vereines Dtsch. Ingenieure 60, 541-546.

Palabiyik, I., Olunloyo, B., Fryer, P.J., Robbins, P.T., 2014. Flow regimes in the emptying of pipes filled with a Herschel-Bulkley fluid. Chem. Eng. Res. Des. 92, 2201-2212. doi:10.1016/j.cherd.2014.01.001

Portalski, S., 1963. Studies of falling liquid film flow: Film thickness on a smooth vertical plate. Chem. Eng. 18, 787-804. doi:10.1016/0009-2509(63)85046-0

Rodgers, A., Boer, G. de, Murray, B., Scott, G., Kapur, N., 2018. An investigation in to batch cleaning using wash racks. Food Bioprod. Process. 113, 118-128. doi:10.1016/j.fbp.2018.11.003 
Wang, T., Davidson, J.F., Wilson, D.I., 2015. Flow patterns and cleaning behaviour of horizontal liquid jets impinging on angled walls. Food Bioprod. Process. 93, 333-342. doi:10.1016/j.fbp.2014.09.006

3

4

5

6

7

Wang, T., Davidson, J.F., Wilson, D.I., 2013a. Effect of surfactant on flow patterns and draining films created by a static horizontal liquid jet impinging on a vertical surface at low flow rates. Chem. Eng. Sci. 88, 79-94. doi:10.1016/j.ces.2012.11.009

Wang, T., Faria, D., Stevens, L.J., Tan, J.S.C., Davidson, J.F., Wilson, D.I., 2013b. Flow patterns and draining films created by horizontal and inclined coherent water jets impinging on vertical walls. Chem. Eng. Sci. 102, 585-601. doi:10.1016/j.ces.2013.08.054

Wilson, D., Köhler, H., L Cai, J.-P.M., Davidson, J., 2015. Cleaning of a model food soil from horizontal plates by a moving vertical water jet. Chem. Eng. Sci. 123, 450-459.

Wilson, D.I., Atkinson, P., Köhler, H., Mauermann, M., Stoye, H., Suddaby, K., Wang, T., Davidson, J.F., Majschak, J.-P., 2014. Cleaning of soft-solid soil layers on vertical and horizontal surfaces by stationary coherent impinging liquid jets. Chem. Eng. Sci. 109, 183-196. doi:10.1016/j.ces.2014.01.034

Wilson, D.I., Köhler, H., Cai, L., Majschak, J.-P., Davidson, J.F., 2015. Cleaning of a model food soil from horizontal plates by a moving vertical water jet. Chem. Eng. Sci. 123, 450-459. doi:10.1016/j.ces.2014.11.006

Wilson, D.I., Le, B.L., Dao, H.D.A., Lai, K.Y., Morison, K.R., Davidson, J.F., 2012. Surface flow and drainage films created by horizontal impinging liquid jets. Chem. Eng. Sci. 68, 449-460. doi:10.1016/j.ces.2011.10.003

Yang, J., Kjellberg, K., Jensen, B.B.B., Nordkvist, M., Gernaey, K. V., Krühne, U., 2019. Investigation of the cleaning of egg yolk deposits from tank surfaces using continuous and pulsed flow. Food Bioprod. Process. 113, 154-167. doi:10.1016/j.fbp.2018.10.007 
(a)

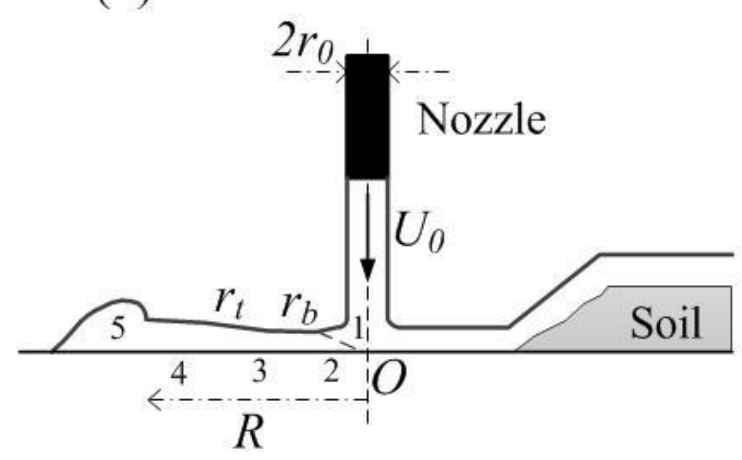

1 - Stagnation region

2 - Boundary layer formation

3 - Laminar region

4 - Turbulent region

5 - Rope (b)

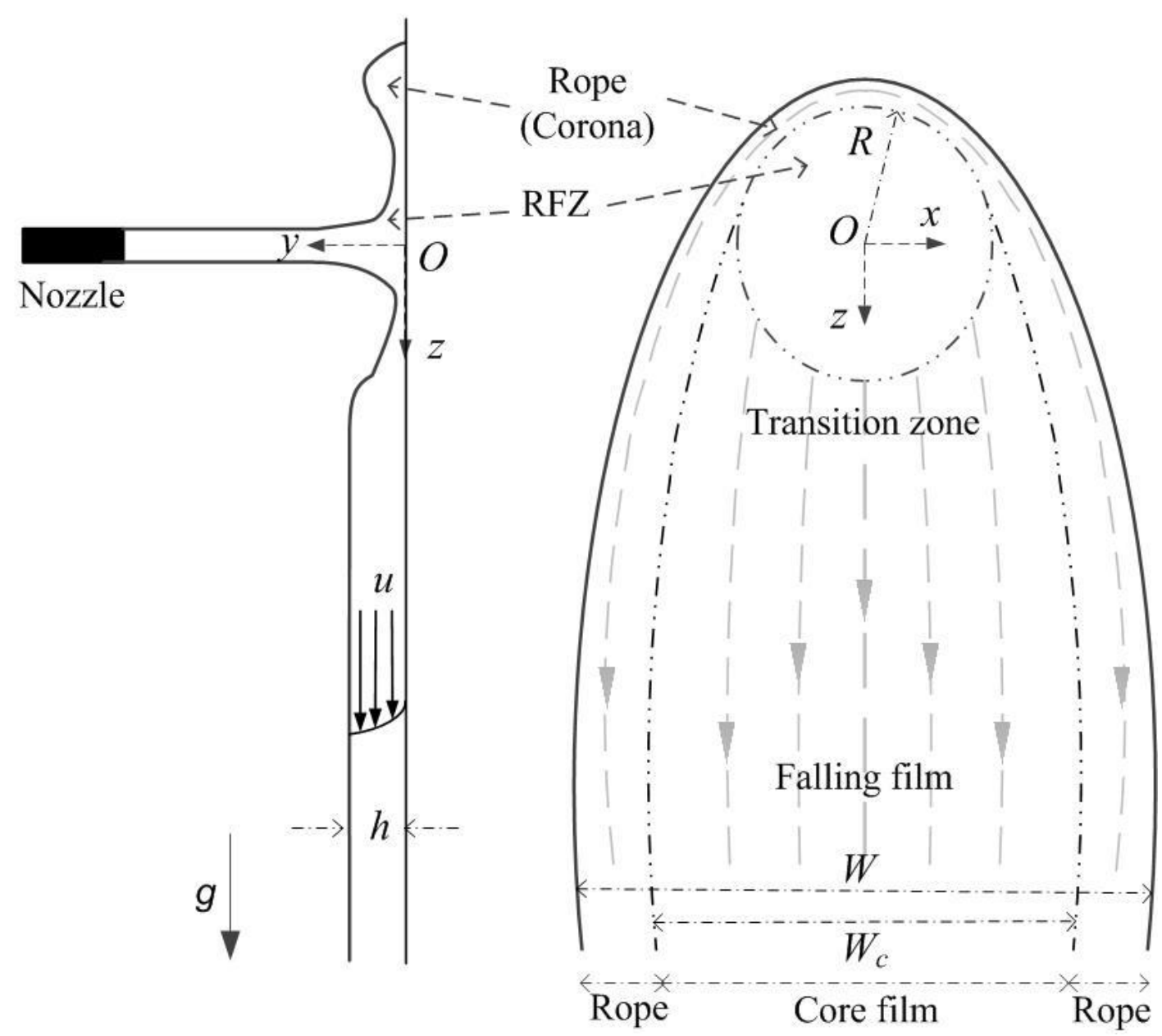

Fig. 1. Schematic of the flow patterns formed by a horizontal jet impinging on a vertical wall: $(a)$ side view of radial flow zone with (right) and without (left) soil, $(b)$ side view of the radial flow zone and the falling film, $(c)$ front view of the radial flow zone and the falling film. $O$ marks the jet impingement point. 
(a)

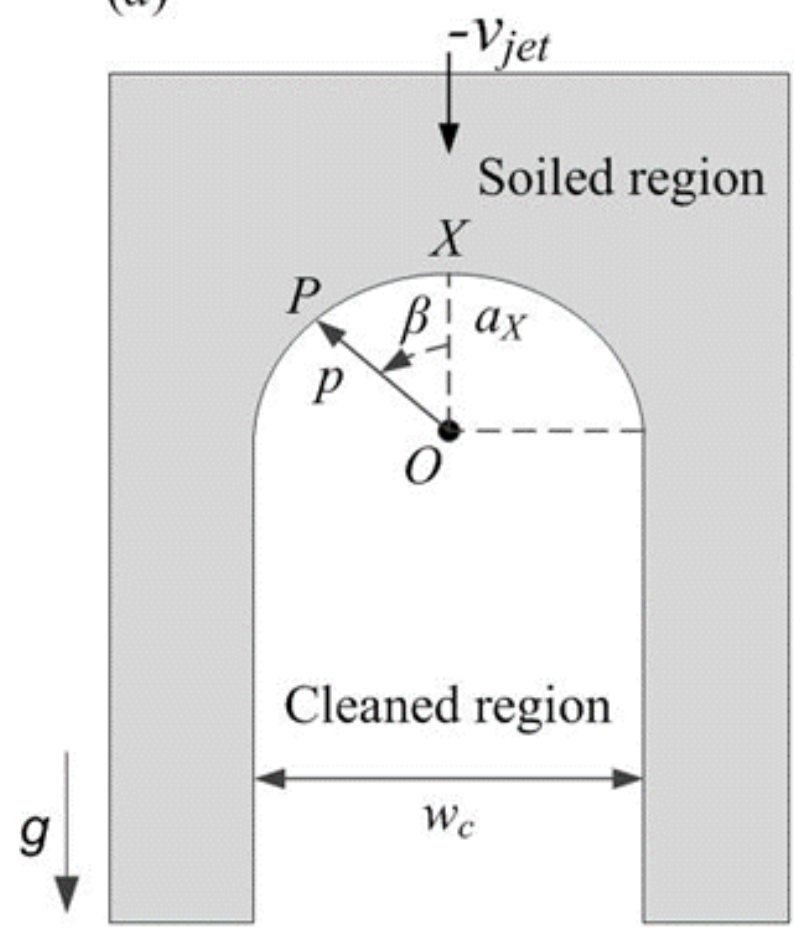

(b)

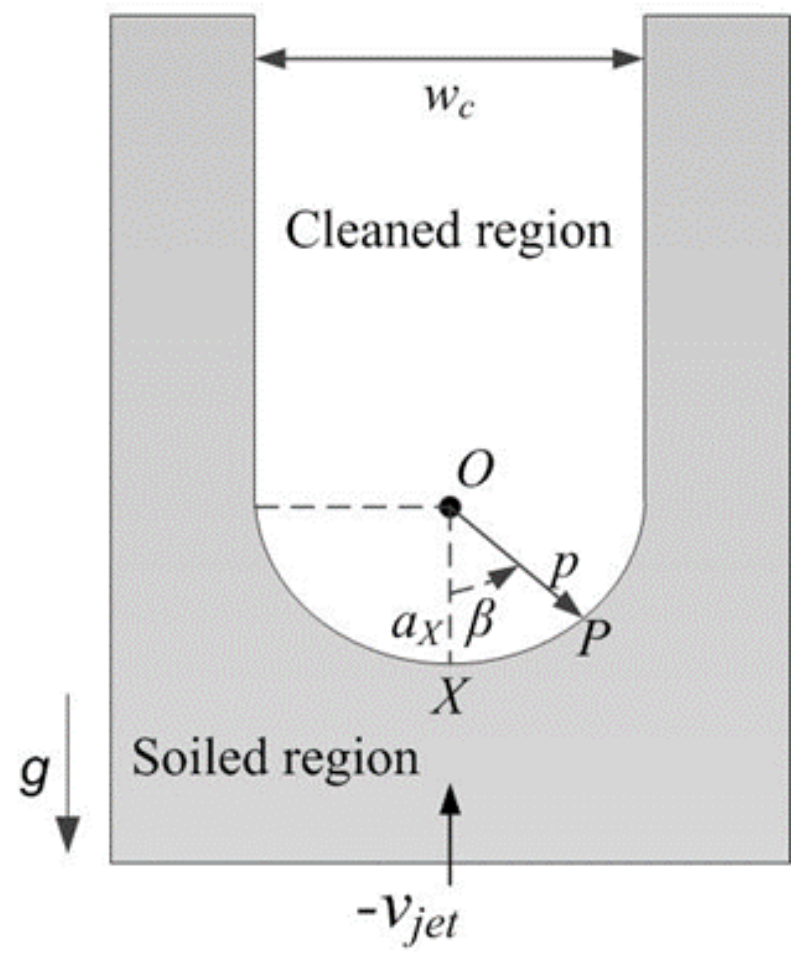




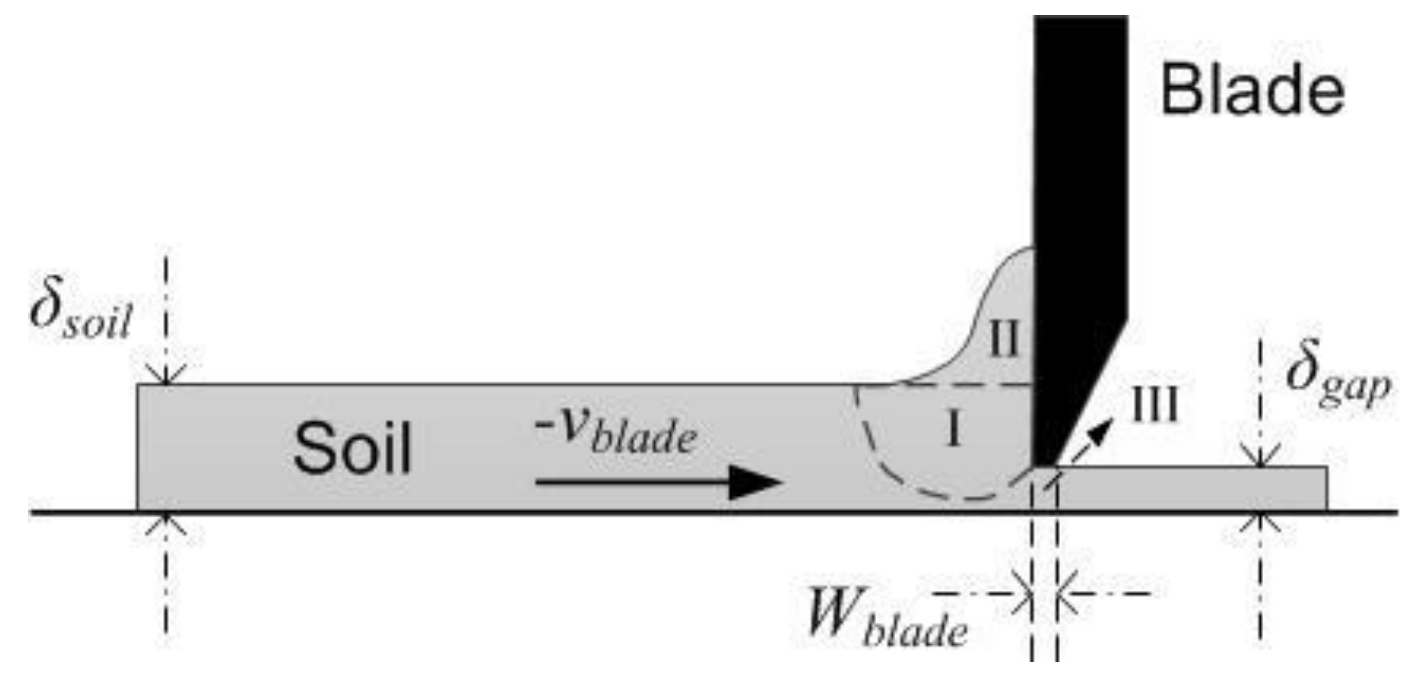

2

3

4 Fig. 3. Schematic of the millimanipulation device. In the experiments, the blade is static and the soiled 5 plate moves towards the blade. Three regions denote the three components of the measured force: (I) to 6 deform the material, (II) to displace the deformed material, (III) to overcome the shear resistance in the 7 gap.

8 


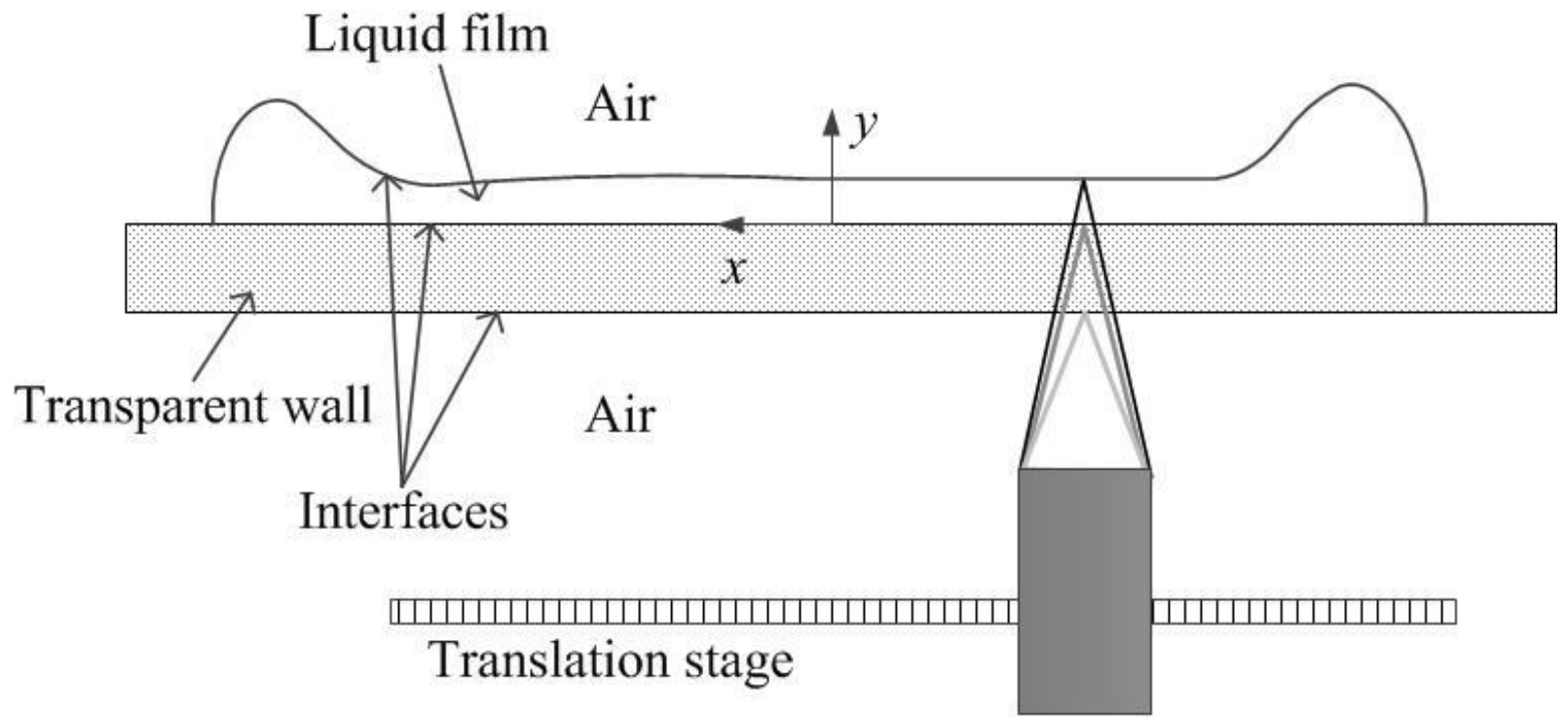

1

CTS sensor

2

3 Fig. 4. Plan view of the configuration for measuring falling film thickness on a vertical wall by the CTS.

4 Measurements were made $15 \mathrm{~cm}$ below the point of jet impingement.

5

6 
(a)

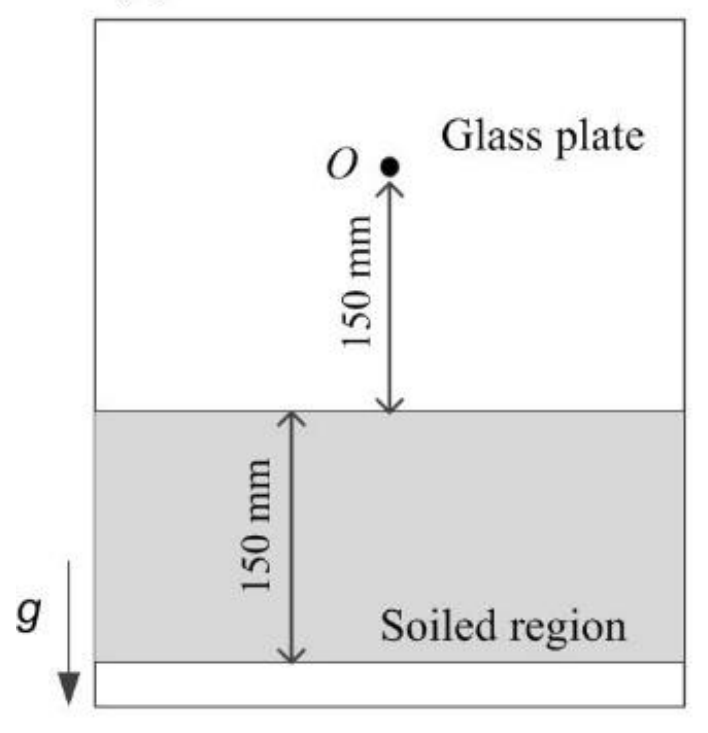

(b)

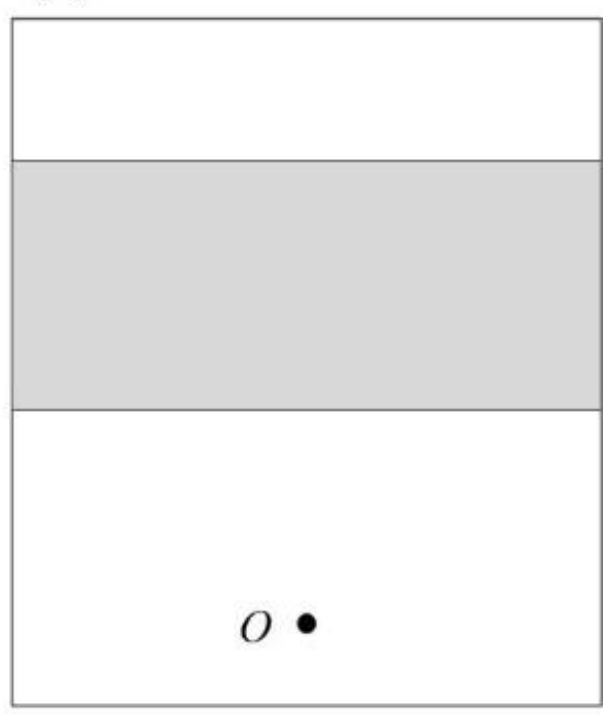

(c)

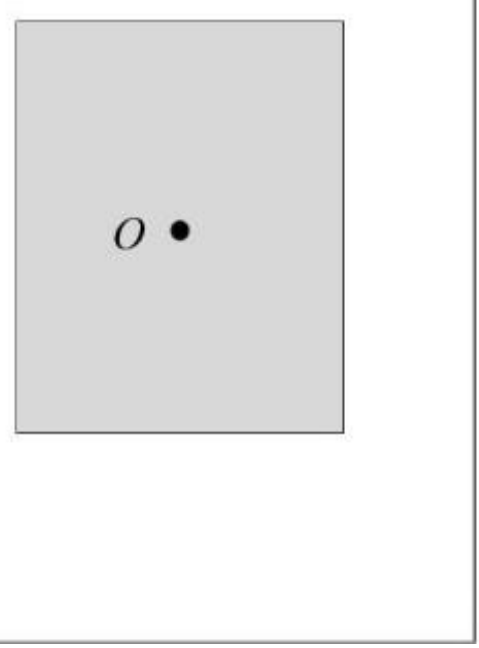

2 Fig. 5. Schematic showing soiled regions and impingement points in experiments investigating cleaning 3 by moving jets and falling films. (a) Impinging above the soiled region, nozzle moving downwards (plate 4 moves upwards); cleaning only by falling films (both nozzle and plate are static, the liquid drains down). 5 (b) Impinging below the soiled region, nozzle moving upwards (plate moves downwards). (c) Impinging 6 on the soiled region, nozzle moving either downwards or upwards (plate moves either upwards or 7 downwards). 


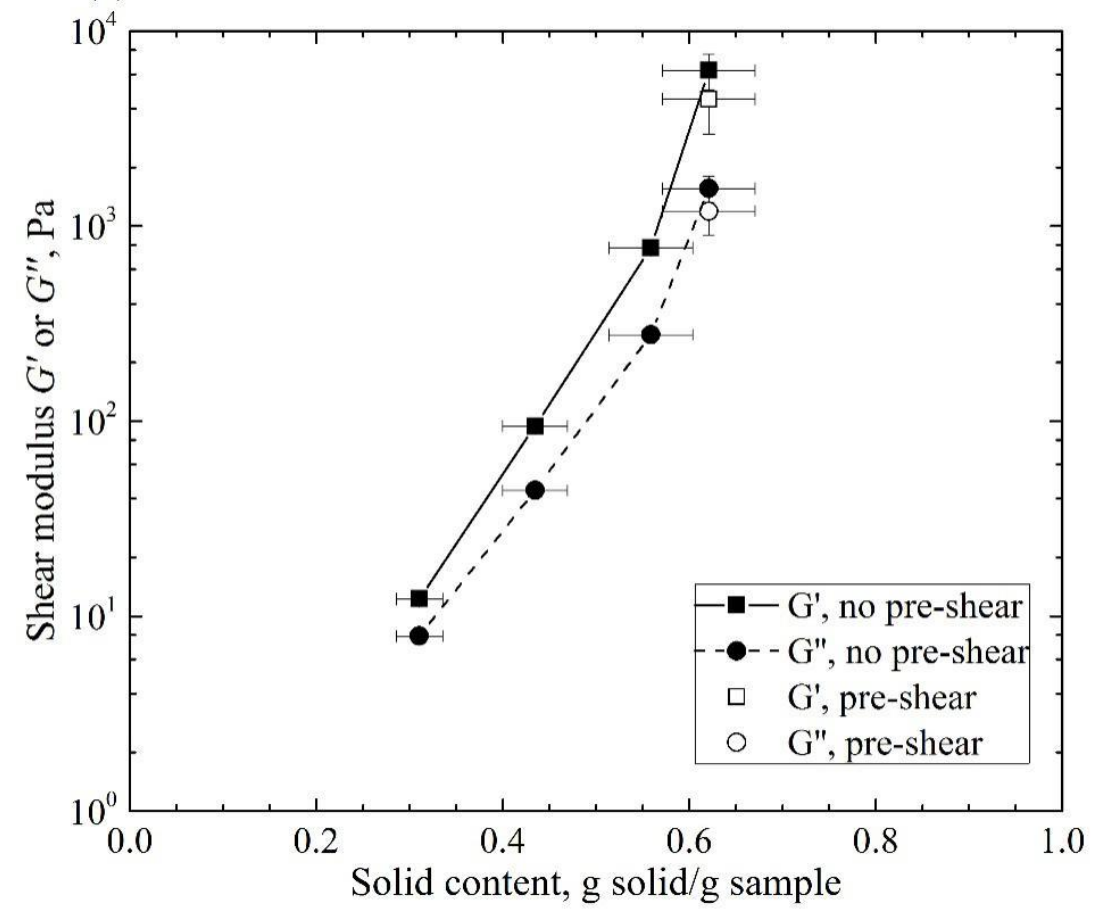

(b)

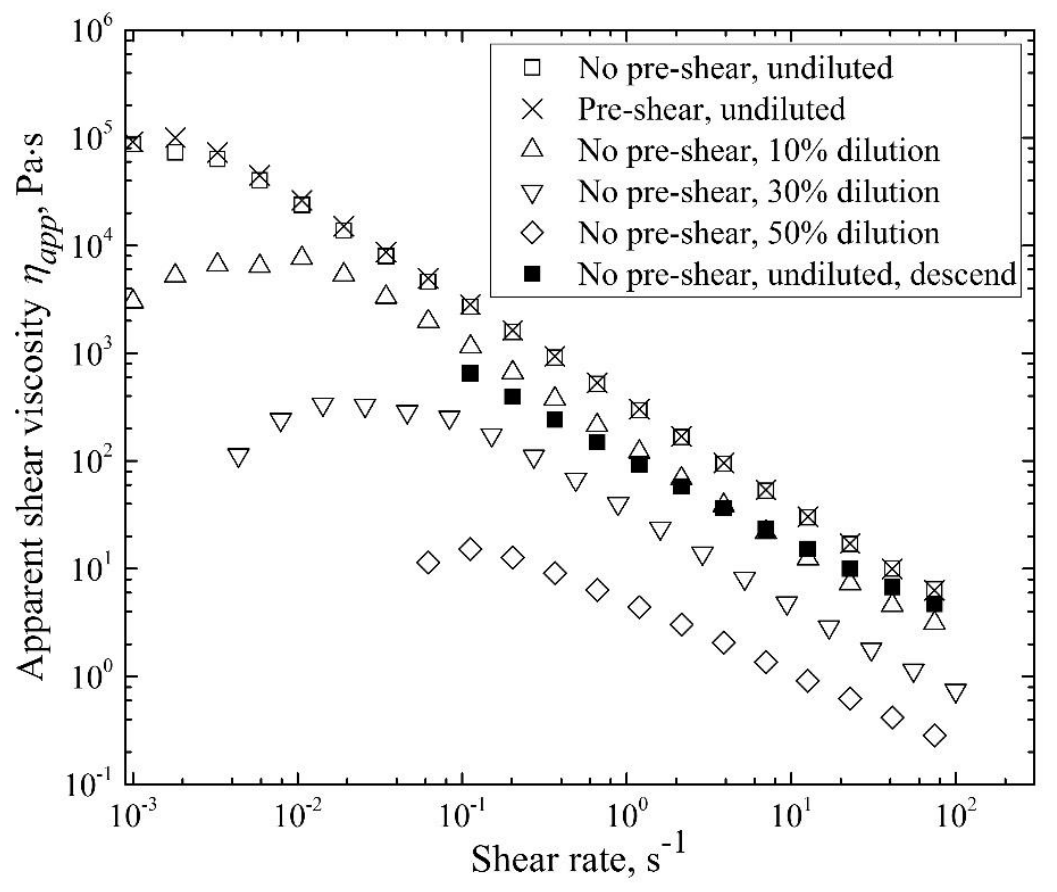

3 Fig. 6. Effect of dilution on (a) shear and elastic moduli of toothpaste measured by oscillatory time sweep 4 at a constant oscillation stress of $0.1 \mathrm{~Pa}$ and frequency of $1 \mathrm{~Hz}$, and $(b)$ apparent viscosity. An increasing 5 shear rate ramp was applied in all cases apart from that labelled descend. 
(a)

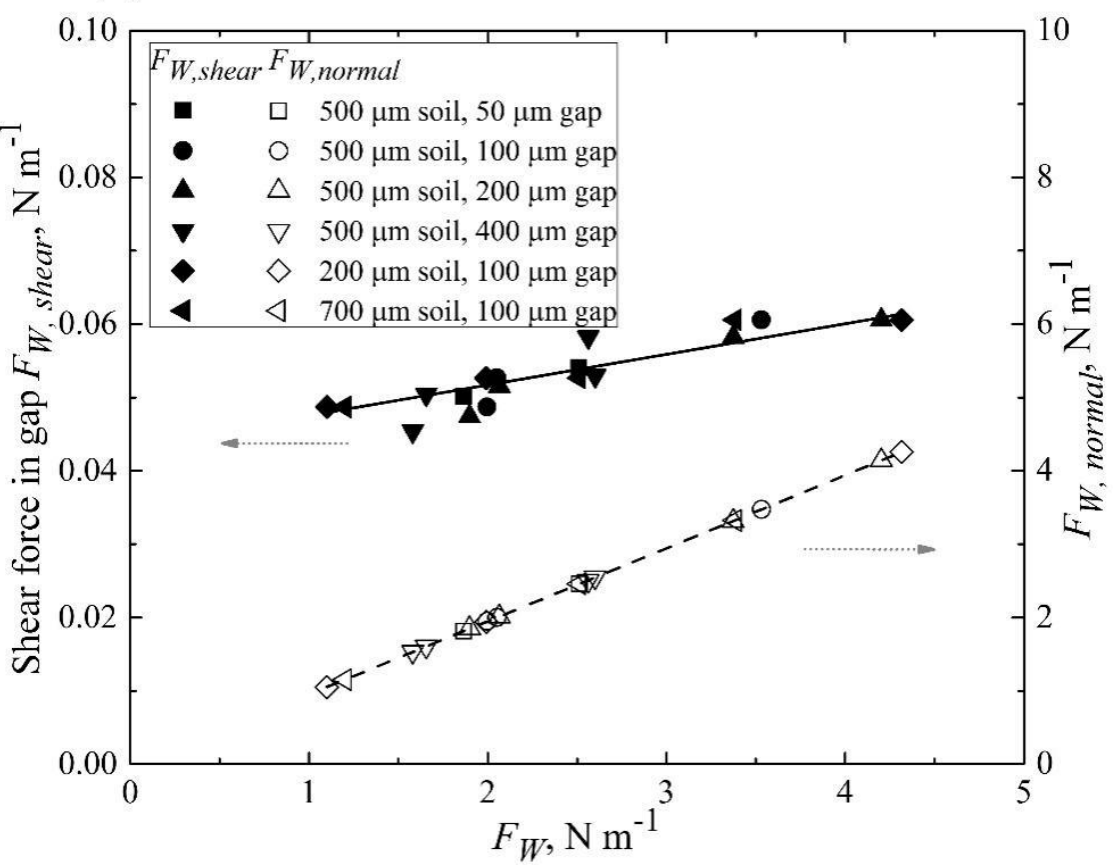

(b)

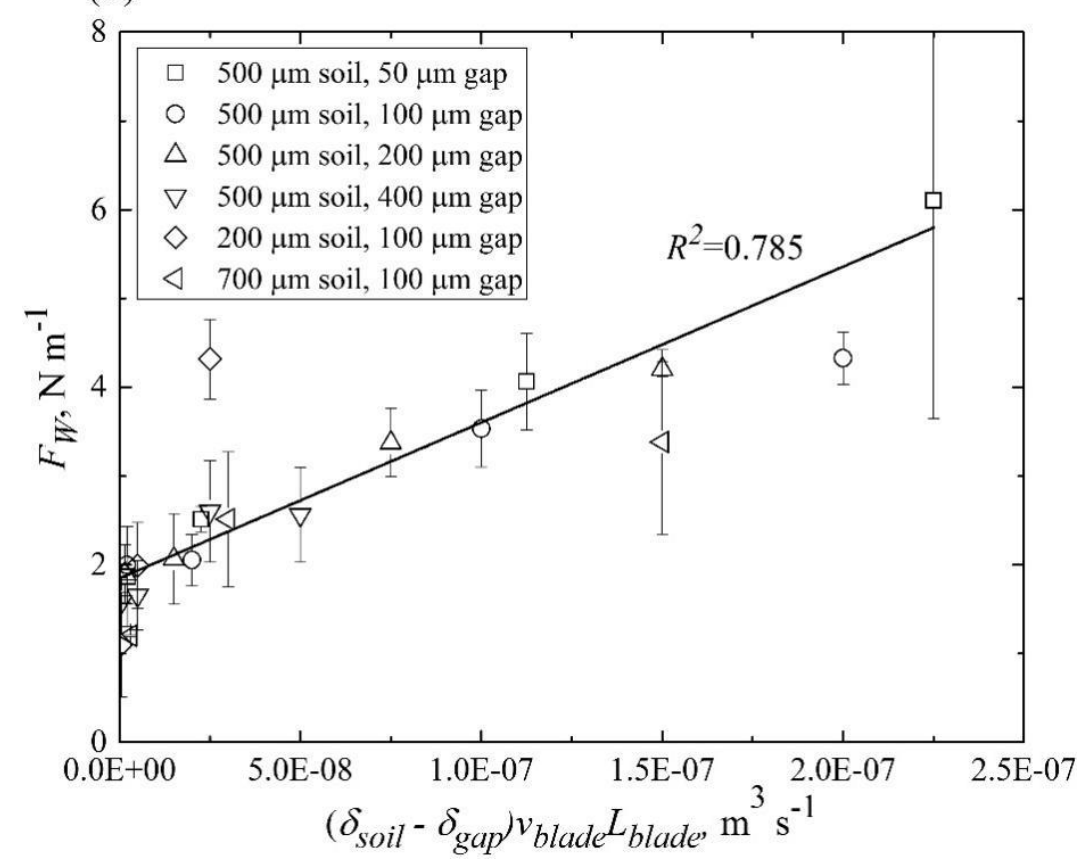

3 Fig. 7. Millimanipulation measurement results. (a) Shear force and normal force as a fraction of the 4 measured force. $(b)$ Measured force required to dislodge volume of soil. Error bars indicate the standard 5 deviation of at least three measurements. 


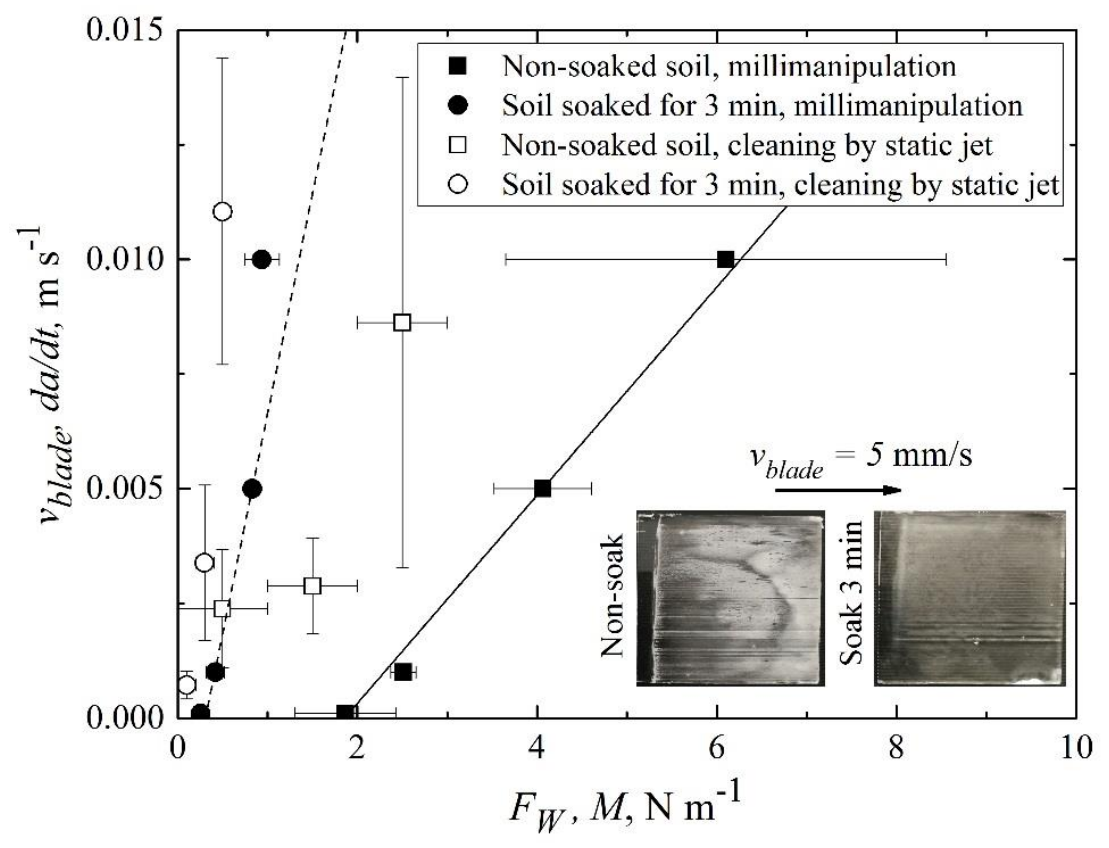

2 Fig. 8. Effect of soaking on the force measured by millimanipulation (solid symbols). Inset photographs 3 show the soiled glass plates after testing: white colour indicates the presence of toothpaste. Initial soil 4 layer thickness $500 \mu \mathrm{m}$, gap beneath blade $50 \mu \mathrm{m}$. The error bar (the error bars for some points are too 5 small to see) indicates the standard deviation of at least three measurements. The millimanipulation 6 results are compared with the cleaning of soils by static jets (open symbols) from

$7 \quad$ Fig. $9(a)$, taking $d a / d t=v_{\text {blade }}$ and $M=F_{W}$. 
(a)

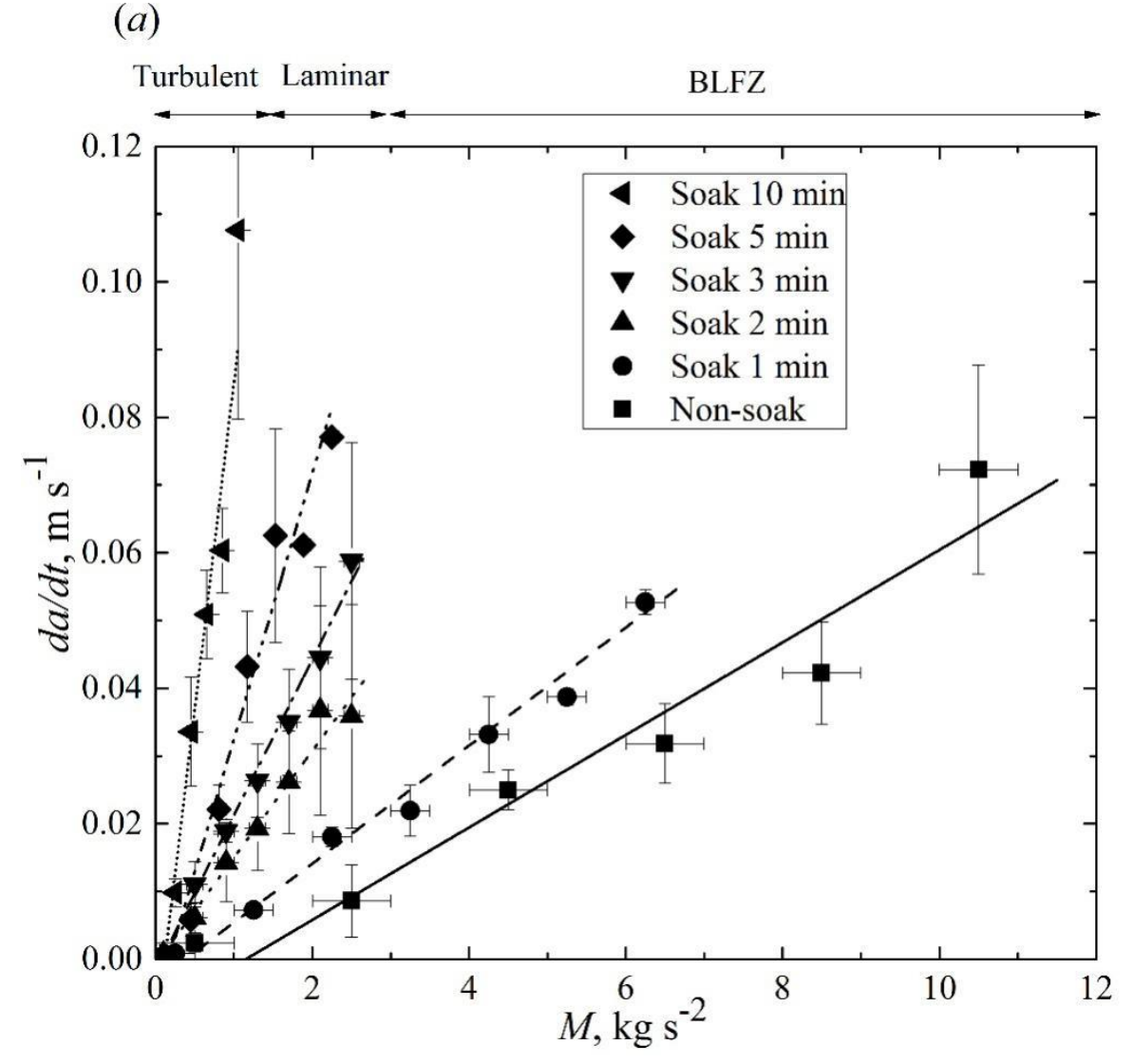

1

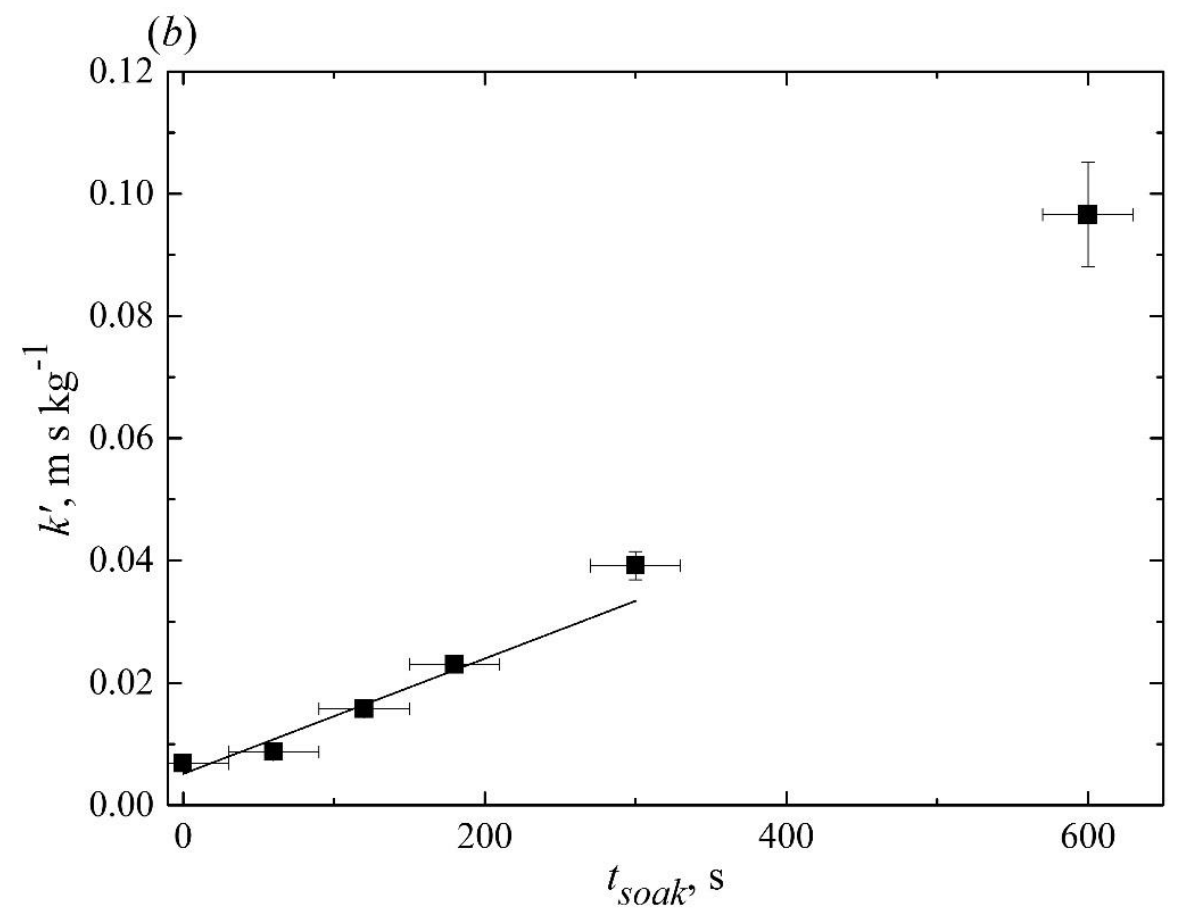

Page 39 of 48 
(c)

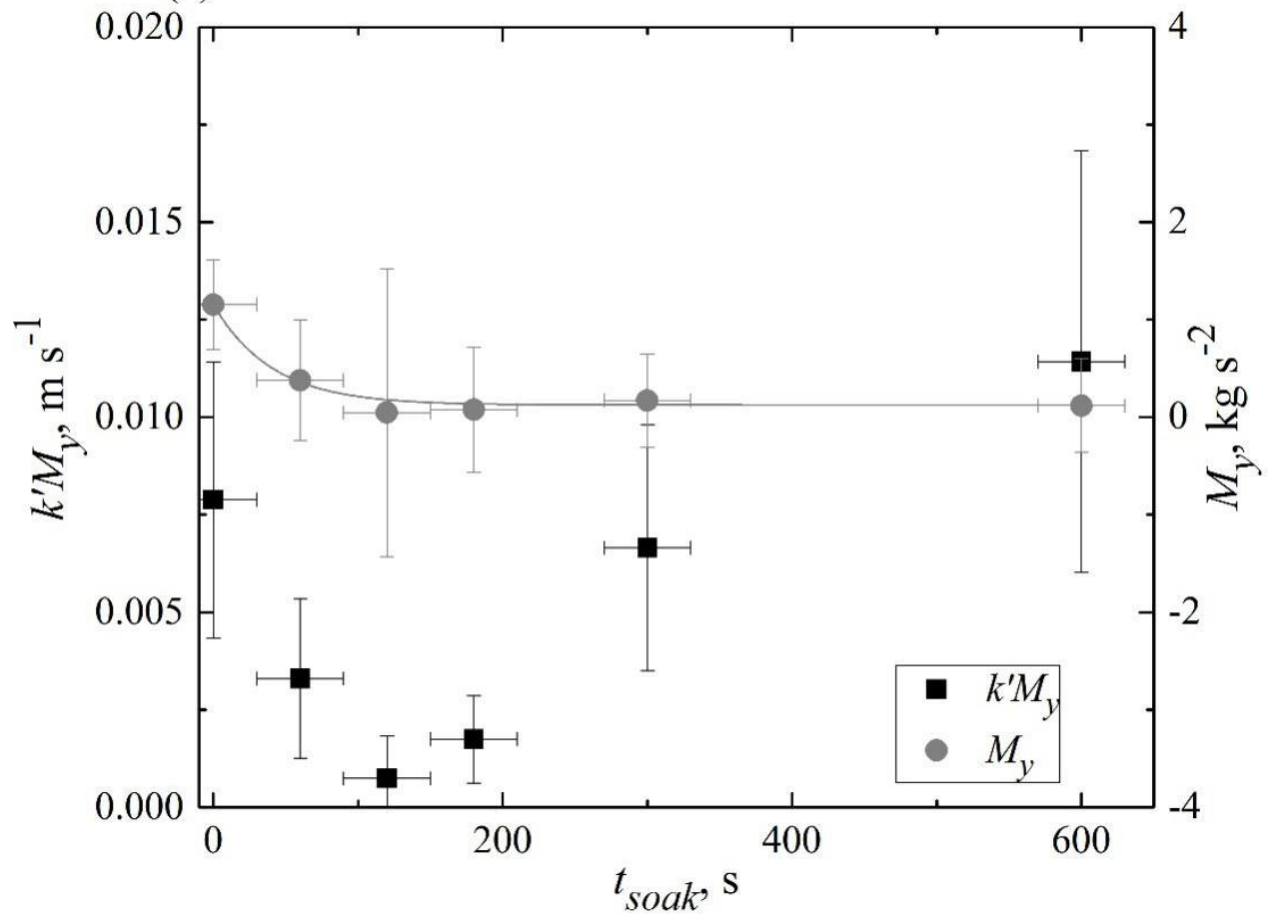

2

3 Fig. 9. Cleaning of toothpaste by water jet $\left(R e_{j}=21200\right)$ from static nozzle. ( $\left.a\right)$ Effect of $M$ on cleaning 4 rate. The values of $M$ for different flow regions are computed by the equations in Table 1 . The gradient 5 of the fitted linear trend lines gives the lumped cleaning rate constant $k^{\prime}$; the intercept is $k^{\prime} M_{y}$. (b) Effect 6 of soaking time on $k^{\prime}$. (c) Effect of soaking time on $k^{\prime} M_{y}$, and the yield momentum required to clean the 7 soil material, calculated using $M_{y}=k^{\prime} M_{y} / k^{\prime}$. The continuous grey line in (c) represents Eq. (18). 


\section{(a)}

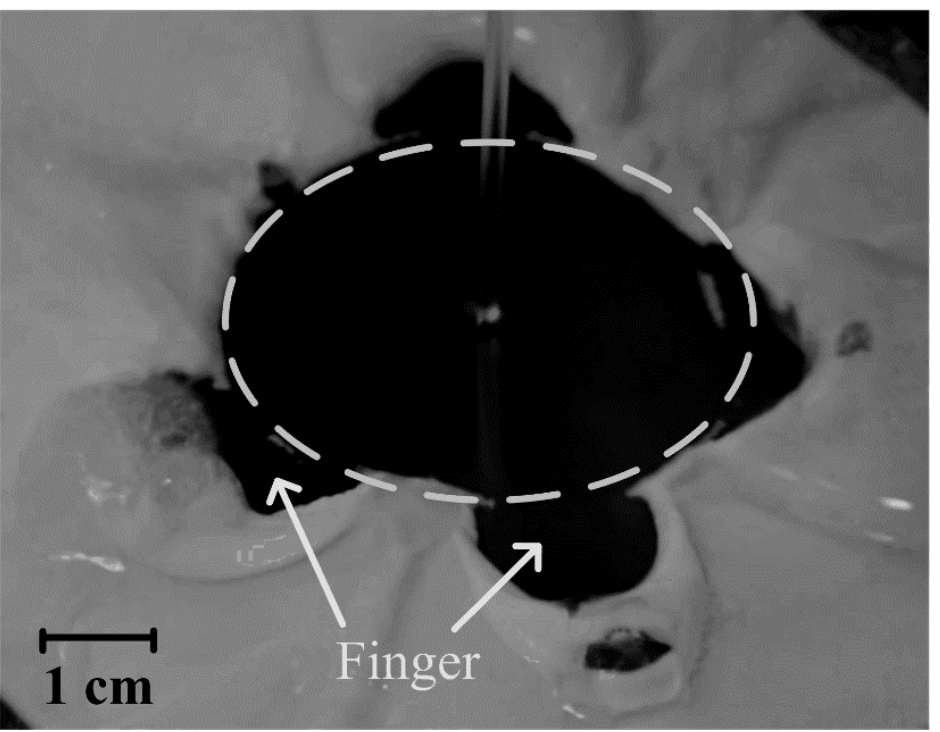

(b)

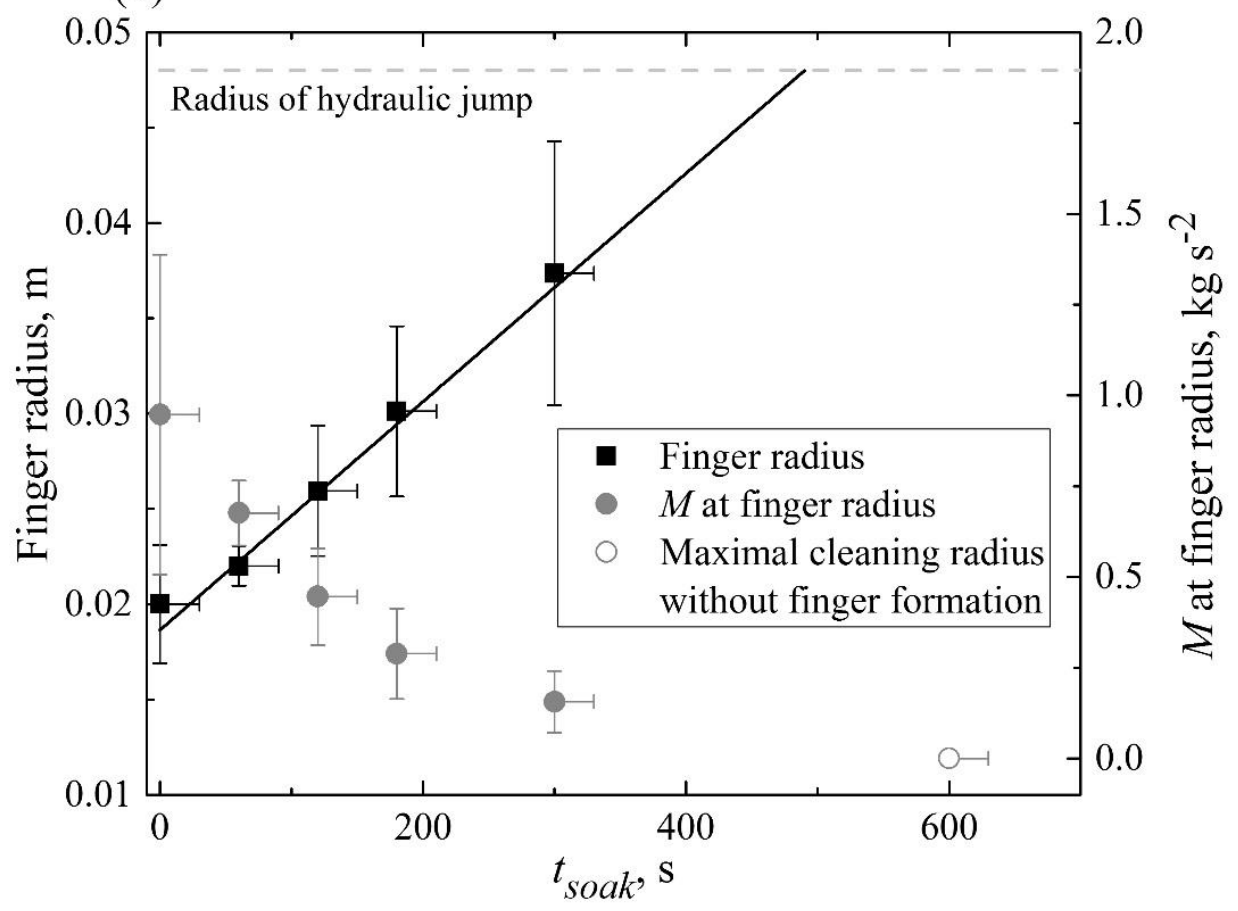

3 Fig. 10. (a) Example of the formation of fingers around the impingement point. The soil is unsoaked 4 toothpaste, and the cleaning time is $3.5 \mathrm{~s}$. (b) Effect of soaking time on the radius where the fingers start 5 to form, and the momentum calculated at the radius of the onset of fingering. 
(a)
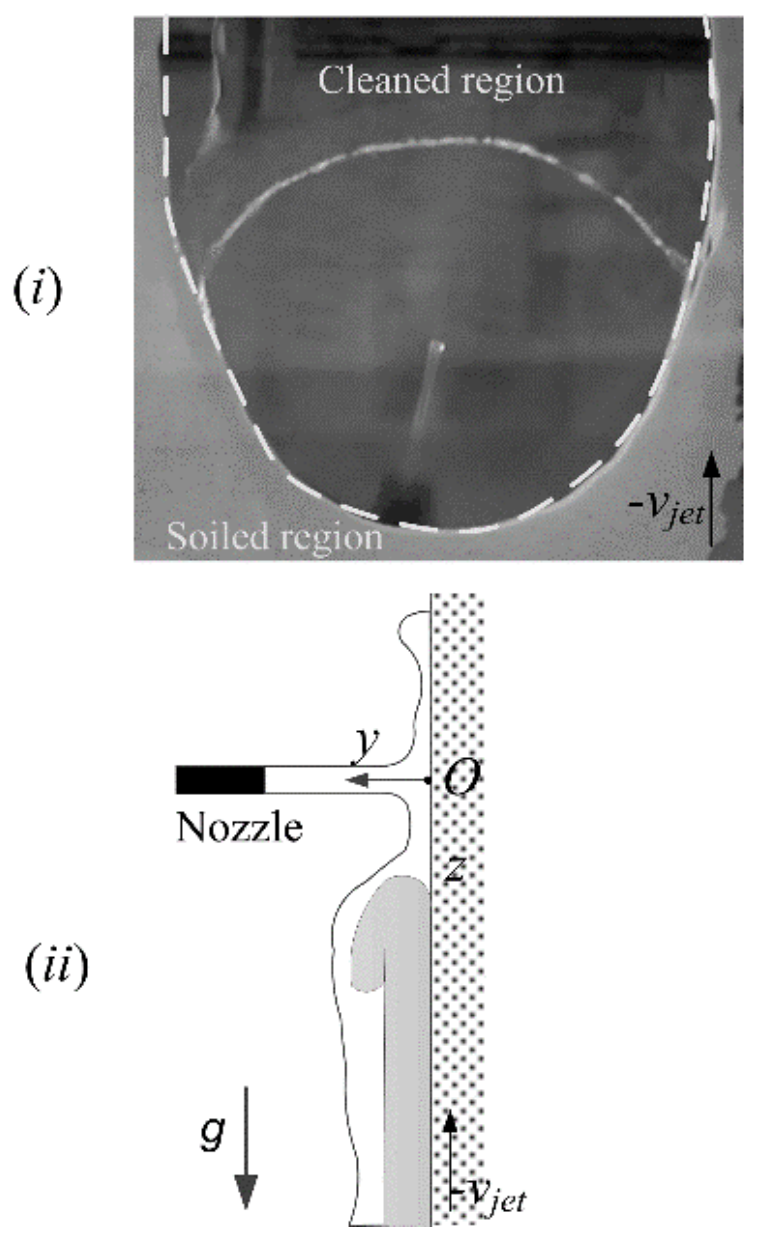

(b)
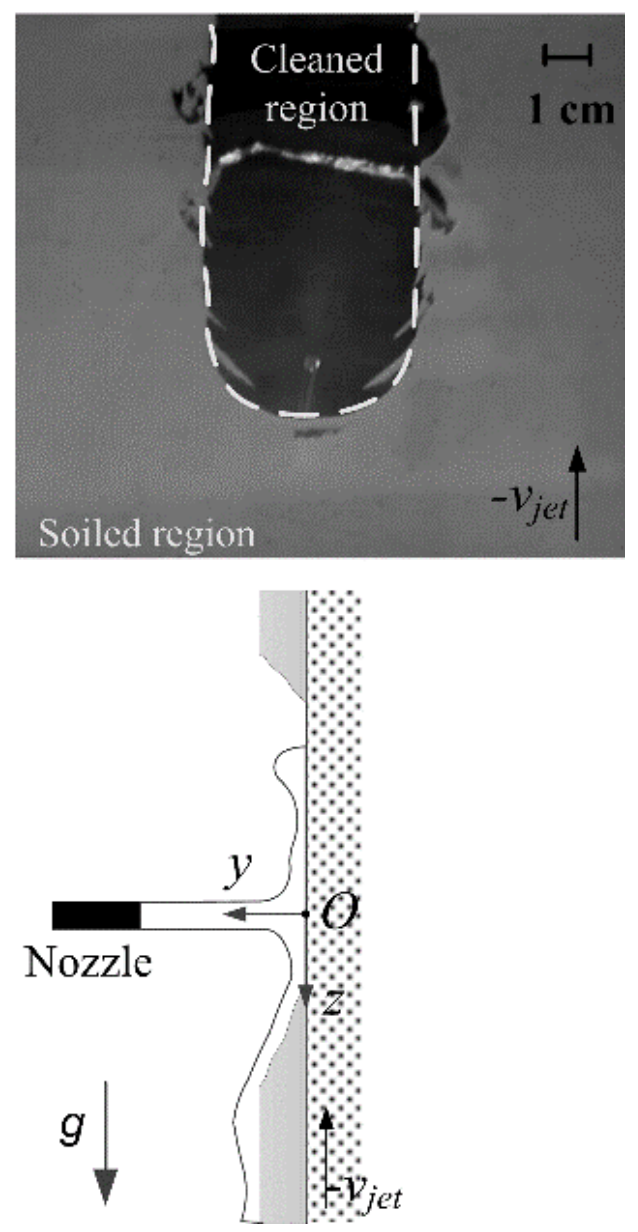

3 Fig. 11. Two mechanisms of cleaning unsoaked toothpaste by jets from moving nozzles: $(a)$ peeling 4 when the jet initially impacts outside the soiled region (as in Fig. 5(a)); (b) contact line erosion when the 5 jet initially impacts within the soiled region (Fig. 5(c)). (i) Photographs from experiments; (ii) schematics. 
(a)

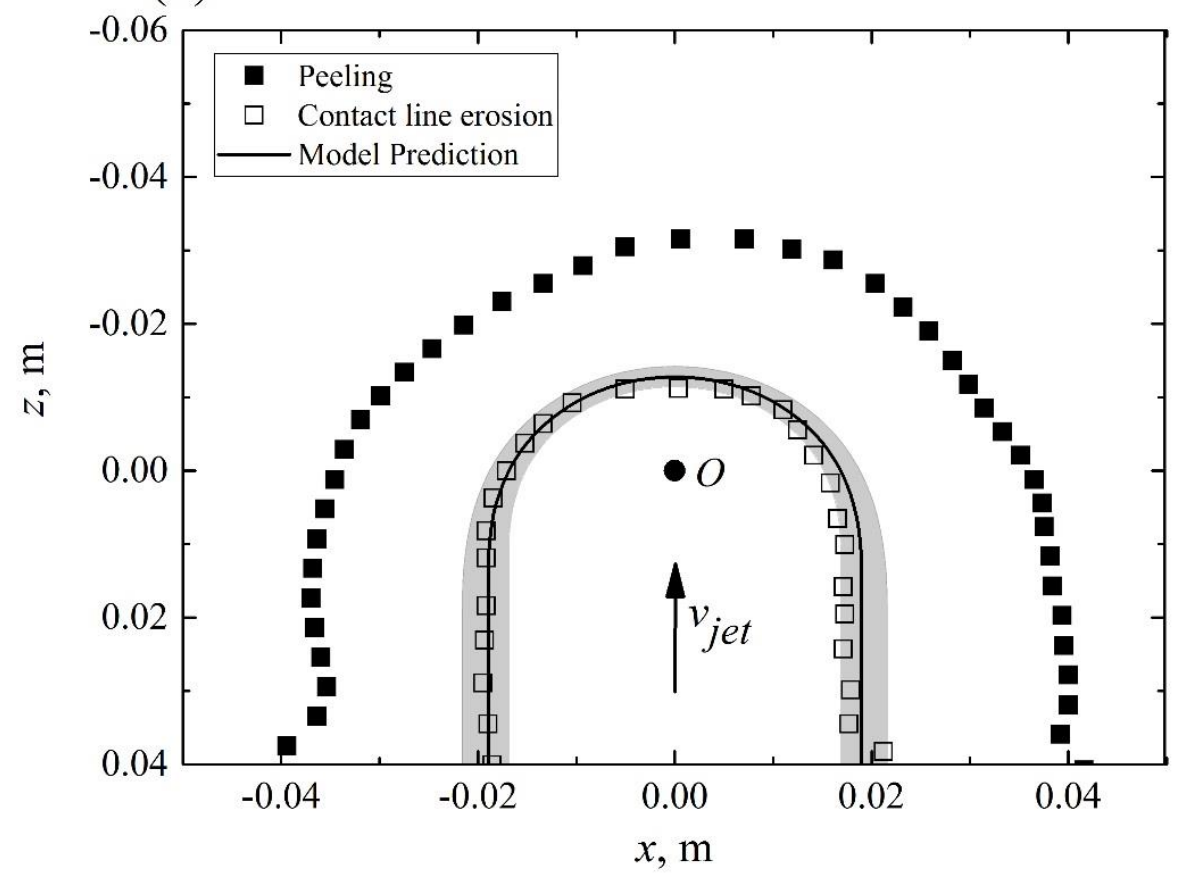

1

(b)

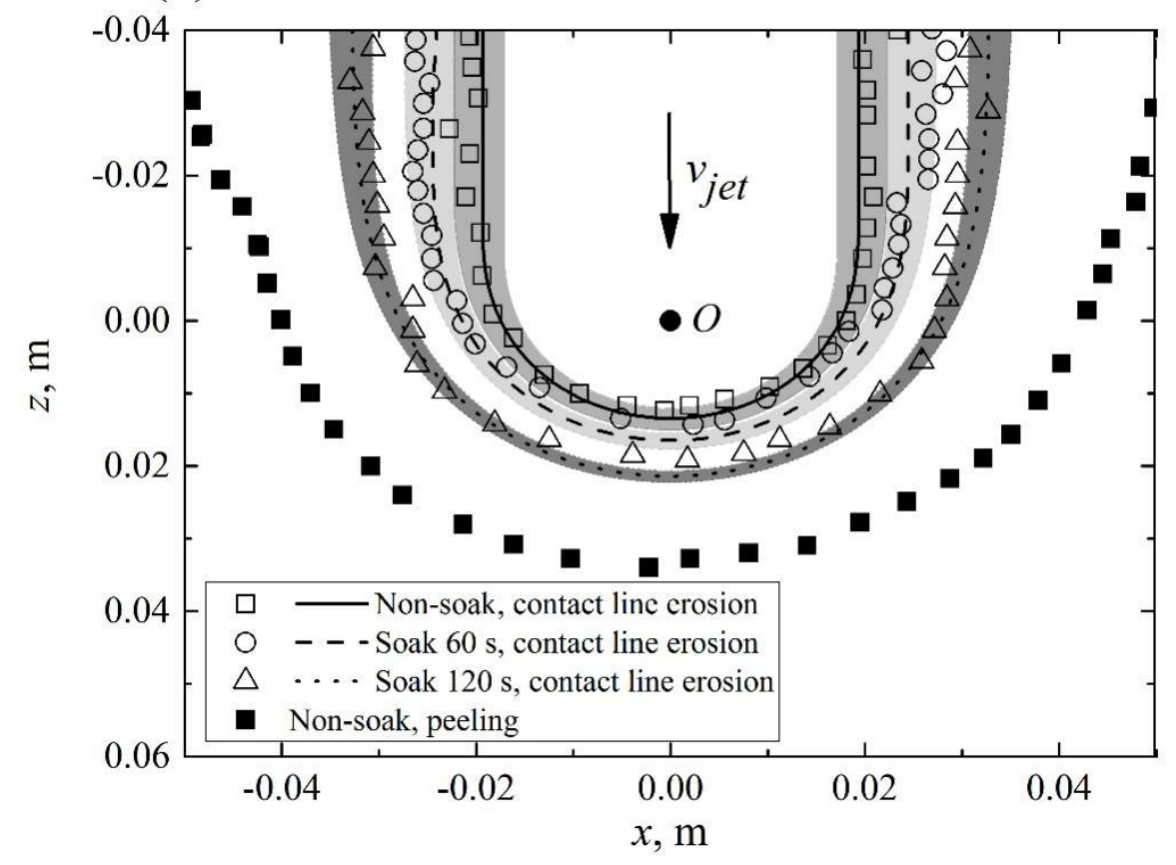

3 Fig. 12. Shape of the cleaning front obtained by experiments and predictions: $(a)$ plate moves downwards 4 at $1.5 \mathrm{~cm} \cdot \mathrm{s}^{-1}$ (jet moves upwards); (b) plate moves upwards at $1.25 \mathrm{~cm} \cdot \mathrm{s}^{-1}$ (jet moves downwards). The 5 symbols and lines are experimental observations and model predictions, respectively. The shaded areas 6 indicate prediction uncertainties caused by the uncertainties in $k^{\prime}$ and $M_{y}$. 


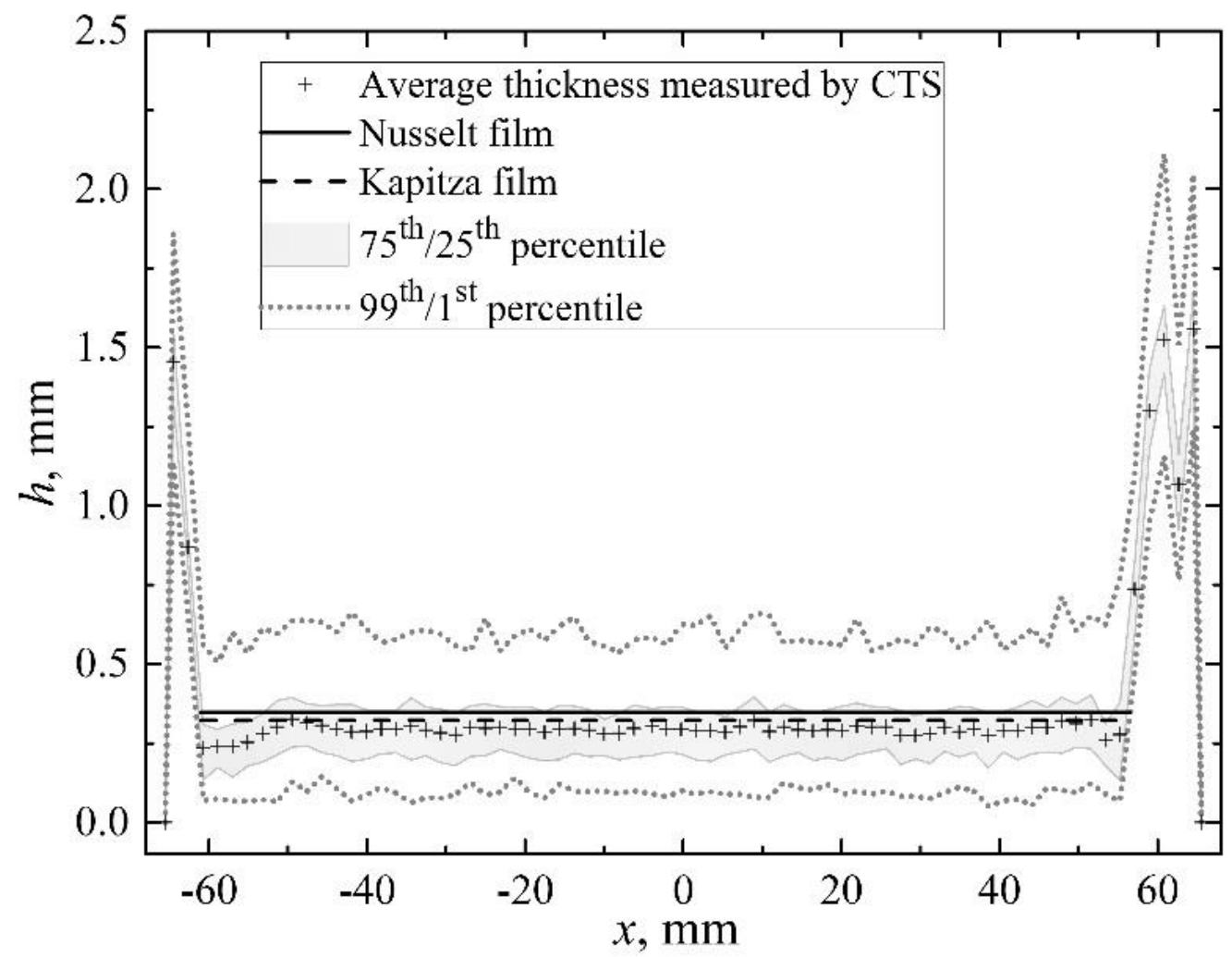

1

2

3 Fig. 13. Film thickness measurements across a falling film, $15 \mathrm{~cm}$ below the impingement point. 4 Conditions: Perspex plate, jet flow rate $2 \mathrm{~L} \cdot \mathrm{min}^{-1}$. The estimated Reynolds number in the core film is $5 R e_{f}=70$. The $75^{\text {th }} / 25^{\text {th }}$ percentile band represents the measurement range of most samples. The $99^{\text {th }} / 1^{\text {st }}$ 6 percentile band represents the maximum and minimum film thickness, respectively. 


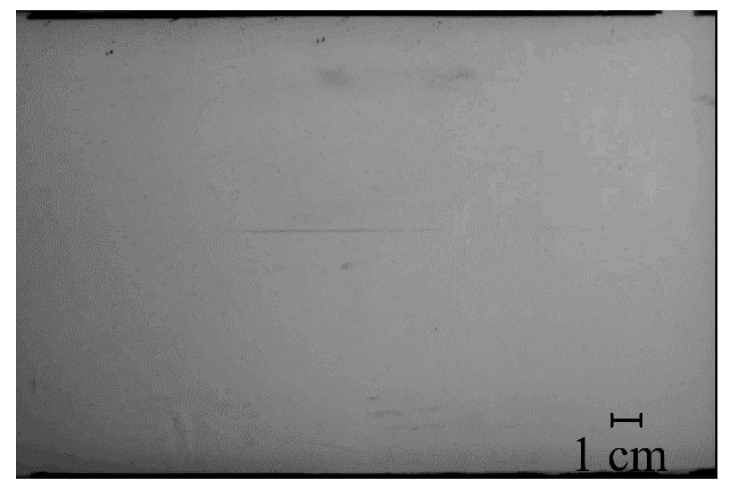

$t=0$

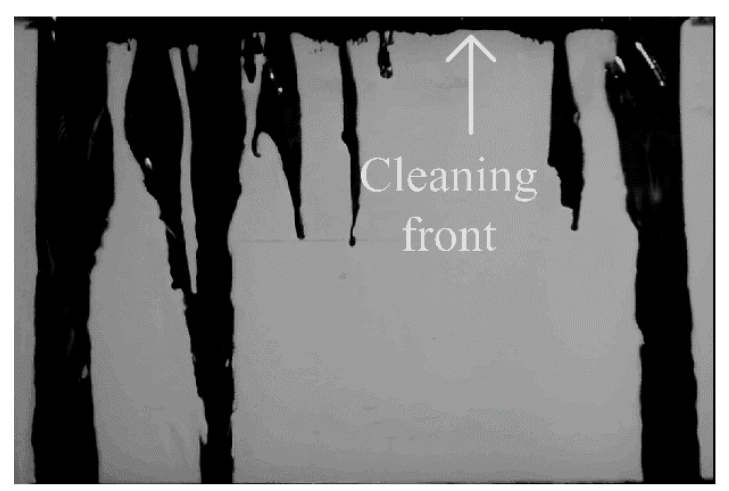

$t=180 \mathrm{~s}$

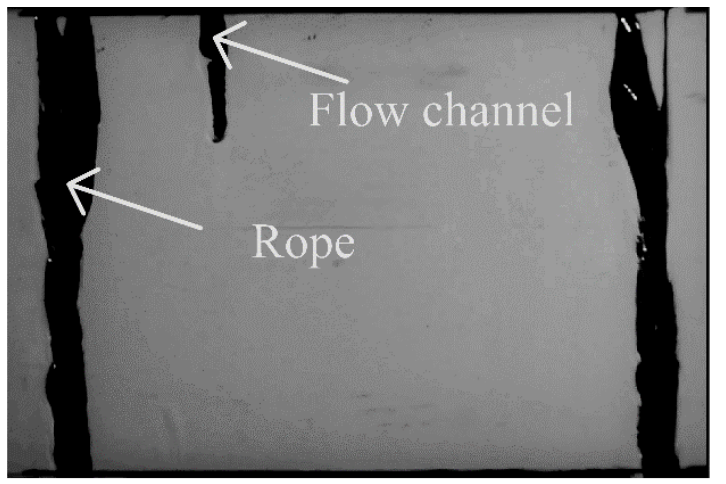

$\mathrm{t}=60 \mathrm{~s}$

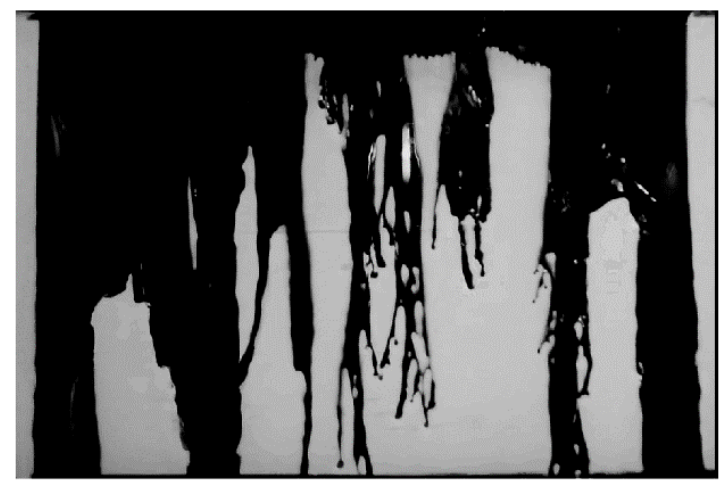

$t=240 \mathrm{~s}$

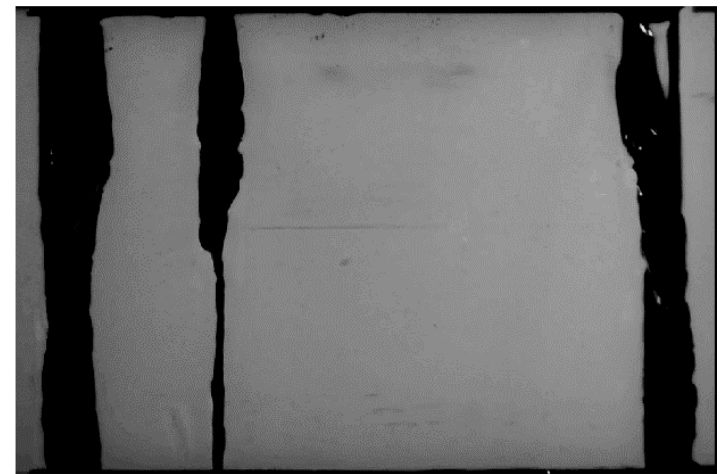

$t=120 \mathrm{~s}$

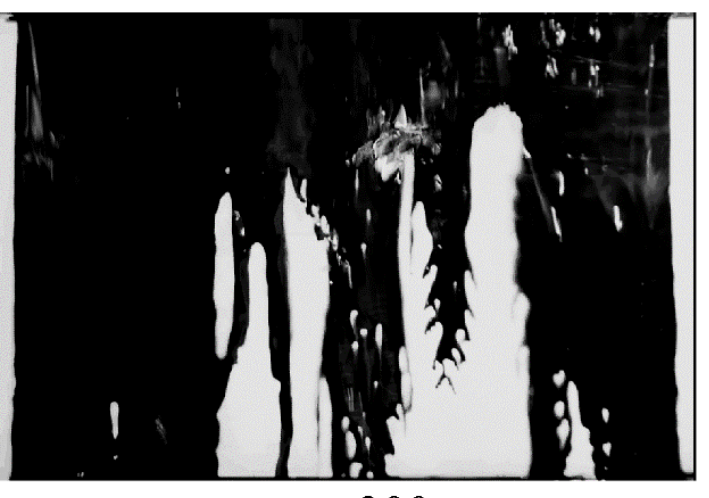

$t=300 \mathrm{~s}$

3 Fig. 14. Cleaning in the falling film region: soiled region located $15-30 \mathrm{~cm}$ below the point of impingement (see Fig. 5(a)). No 4 pre-soaking, jet flow rate $2 \mathrm{~L} \cdot \mathrm{min}^{-1}$. Black indicates all toothpaste has been removed. $t$ is the time since jet impingement started. 5 Salient features marked. 


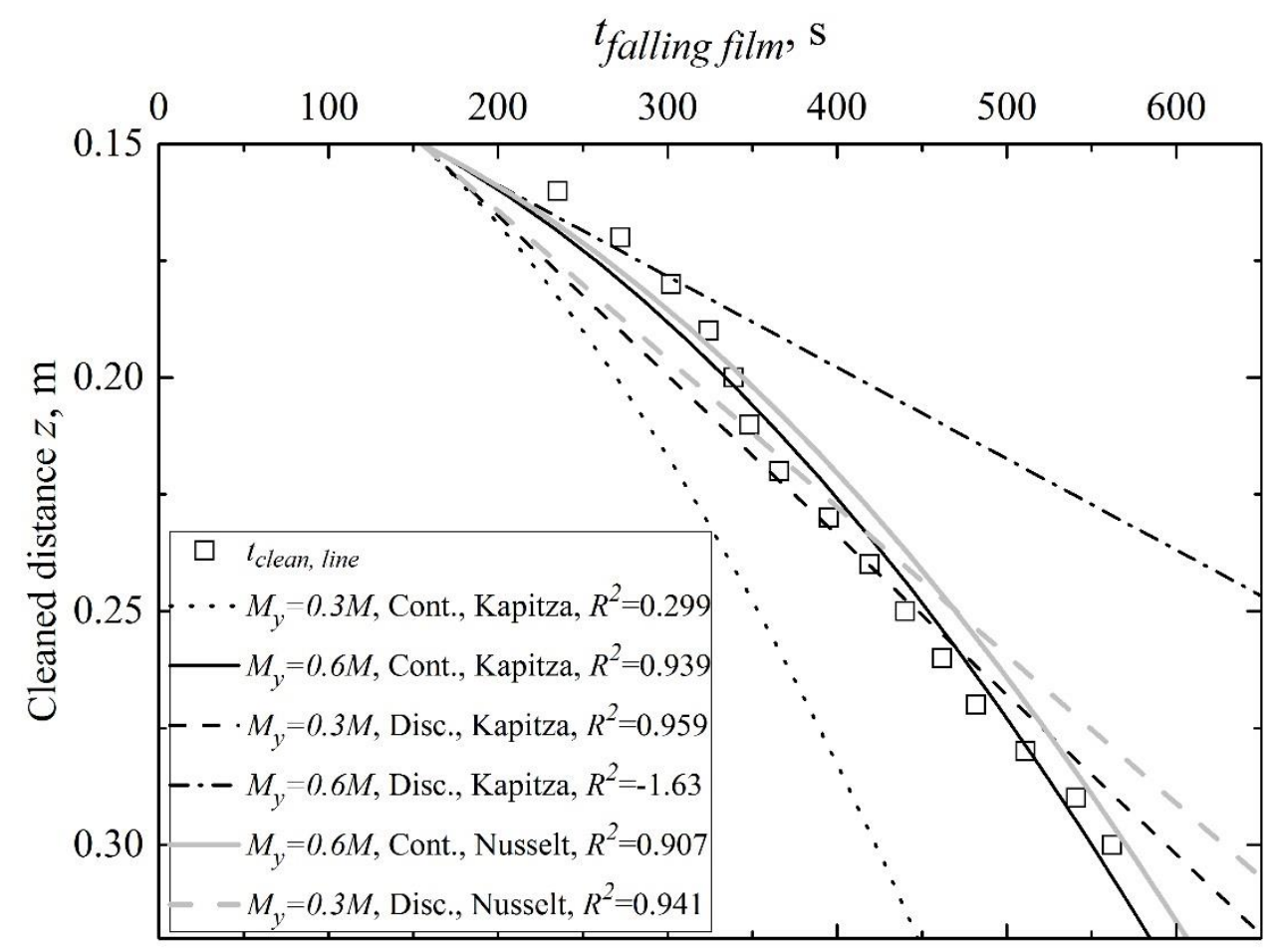

1

2

3 Fig. 15. An example of cleaning times and the fitting of the adhesive removal model based on Nusselt 4 and Kapitza film theories and continuous or discontinuous soaking mechanisms. The flow rate is $2 \mathrm{~L} \cdot \mathrm{min}^{-}$ $5 \quad{ }^{1} . t_{i}=155 \mathrm{~s}$ based on the experiment. 
(a)

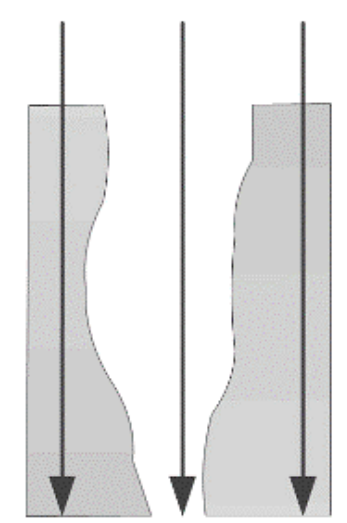

\section{Continuous} soaking (b)

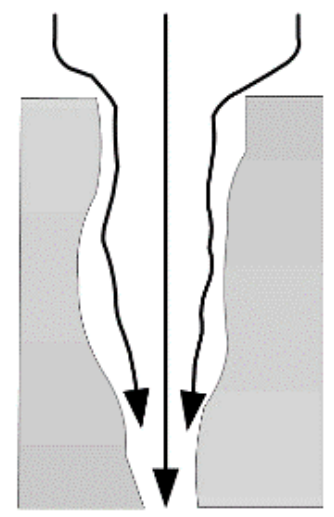

Discontinuous soaking

3 Fig. 16. Two cleaning scenarios by core falling films: $(a)$ continuous soaking, $(b)$ discontinuous soaking. 


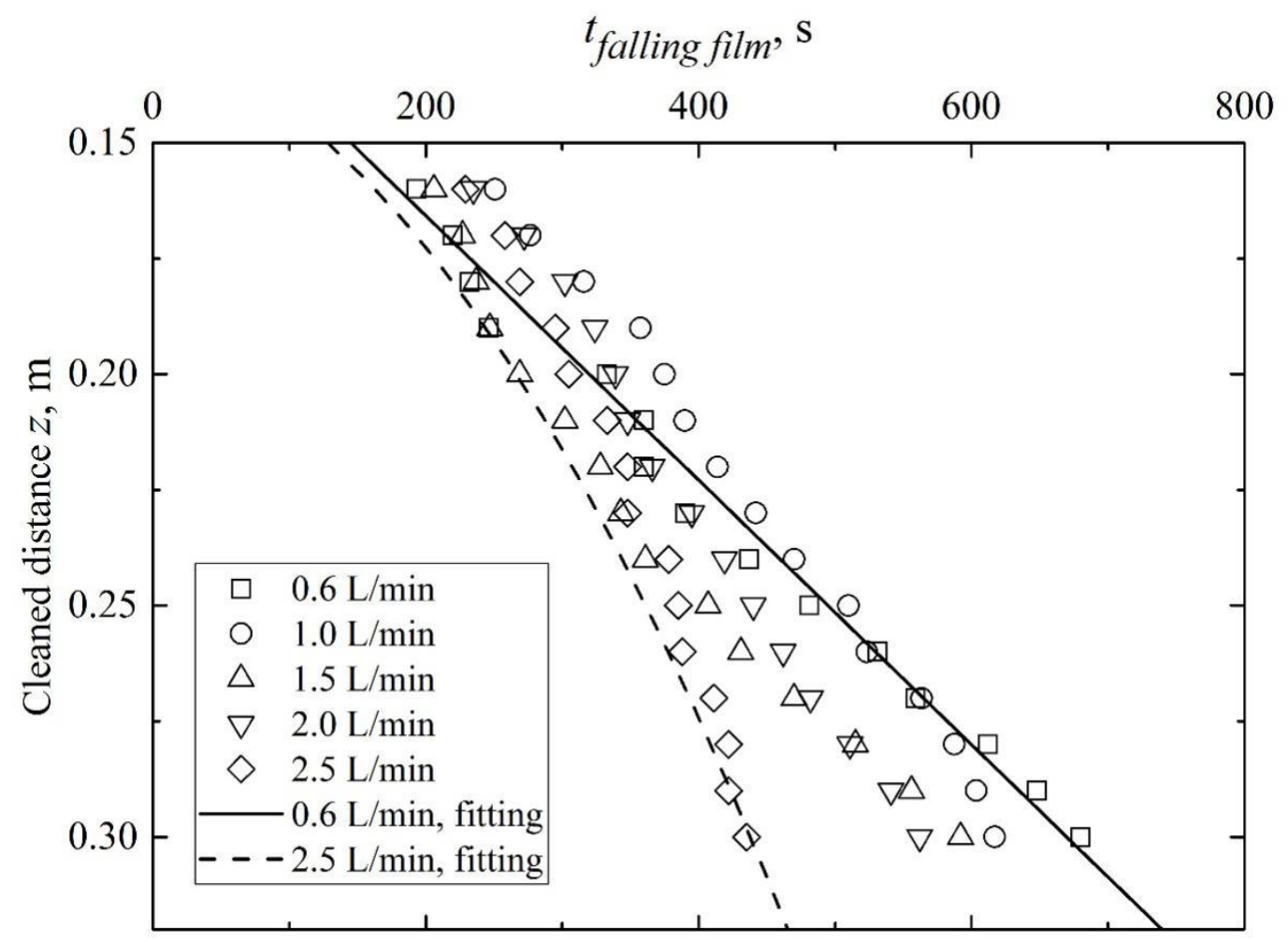

1

2

3 Fig. 17. Line-based cleaning times at different flow rates as well as the adhesive removal model. At 0.6 $4 \mathrm{~L} \cdot \mathrm{min}^{-1}$, only discontinuous soaking applies with $t_{i}=145 \mathrm{~s}$ and $M_{y}=0.7 M$. At $2.5 \mathrm{~L} \cdot \mathrm{min}^{-1}$, continuous 5 soaking applies with $t_{i}=128 \mathrm{~s}$ and $M_{y}=0.7 M$. The film thickness is determined using Kapitza's theory. 